\author{
Universidade de SÃo PaUlo \\ FFCLRP - DEPARTAMENTO DE FísICA \\ Pós-graduaÇão Em Física APlicada À Medicina e Biologia
}

JULIO GODELI NETO

\title{
Simulação de Mamografia Digital por Dupla Energia para Imagens Quantitativas
}

Dissertação apresentada à Faculdade de Filosofia, Ciências e Letras de Ribeirão Preto da Universidade de São Paulo, como parte das exigências para a obtenção do título de Mestre em Física Médica, Área: Física aplicada à Medicina e Biologia.

Ribeirão Preto - SP 2016 


\section{JULIO GODELI NETO}

\section{Simulação de Mamografia Digital por Dupla Energia para Imagens Quantitativas}

Dissertação apresentada à Faculdade de Filosofia, Ciências e Letras de Ribeirão Preto da Universidade de São Paulo, como parte das exigências para a obtenção do título de Mestre em Física Médica.

Área de Concentração:

Física aplicada à Medicina e Biologia.

Orientador:

Martin Eduardo Poletti.

Versão corrigida

Versão original disponível na FFCLRP - USP

Ribeirão Preto - SP

2016 
Autorizo a reprodução e divulgação total ou parcial deste trabalho, por qualquer meio convencional ou eletrônico, para fins de estudo e pesquisa, desde que citada a fonte.

\section{FICHA CATALOGRÁFICA}

Godeli Neto, Julio

Simulação de Mamografia Digital por Dupla Energia para Imagens Quantitativas / Julio Godeli Neto; orientador Martin Eduardo Poletti. Ribeirão Preto - SP, 2016.

85 f.:il.

Dissertação (Mestrado - Programa de Pós-graduação em Física aplicada à Medicina e Biologia) - Faculdade de Filosofia, Ciências e Letras de Ribeirão Preto da Universidade de São Paulo, 2016.

1. Mamografia; 2. Simulação; 3. Dupla-Energia; 4. Quantificação; 5. Otimização. 
Nome: Godeli Neto, Julio

Título: Simulação de Mamografia Digital por Dupla Energia para Imagens Quantitativas

Dissertação apresentada à Faculdade de Filosofia,

Ciências e Letras de Ribeirão Preto da Universidade de São Paulo, como parte das exigências para a obtenção do título de Mestre em Física Médica.

Aprovado em:

\section{Banca Examinadora}

$\operatorname{Prof}(\mathrm{a}) \cdot \operatorname{Dr}(\mathrm{a})$ Instituição:

Julgamento:

Assinatura:

$\operatorname{Prof}(\mathrm{a}) \cdot \operatorname{Dr}(\mathrm{a})$

Instituição:

Julgamento:

Assinatura:

Prof(a). Dr(a).

Instituição:

Julgamento:

Assinatura: 
Dedico este trabalho à minha mãe, Cleusa, por ter se dedicado a me dar a melhor educação possível ao longo da minha vida. 


\section{Agradecimentos}

À minha mãe, Cleusa e minhas irmãs, Adriana e Laura, pelo apoio e conforto familiar que me proporcionaram ao longo dos anos;

À minha namorada, Tatiane, que esteve comigo e me apoiou durante todo este período acadêmico e me incentivou a lutar pelos meus interesses;

Ao meu orientador, Prof.Dr.Martin Eduardo Poletti, pela orientação, paciência e dedicação que me proporcionou para a realização deste trabalho;

Ao Lucas, por proporcionar grande auxílio ao longo do meu mestrado.

Aos companheiros de laboratório, Alex, Leonardo, Daniel, Michel, Jessica e Matheus, pelas experiências compartilhadas em todos os momentos;

Aos meus amigos, Renan, Rodrigo, Jéssica, Daniel, Euclydes e Mariana, pelo companheirismo que me proporcionaram desde a graduação;

Aos professores do curso de graduação em Física Médica, pelo departamento de Física da Faculdade de Filosofia, Ciências e Letras de Ribeirão Preto, que contribuíram significativamente para minha formação;

Ao CIRP, pela autorização do uso do Cluster;

À CAPES pelo apoio financeiro; 


\section{Resumo}

\section{GODELI, J. Simulação de Mamografia Digital por Dupla Energia para}

Imagens Quantitativas. 2016. 85 f. Dissertação (Mestrado - Programa de Pós-graduação em Física aplicada à Medicina e Biologia) - Faculdade de Filosofia, Ciências e Letras de Ribeirão Preto, Universidade de São Paulo, Ribeirão Preto SP, 2016.

A técnica de mamografia por dupla energia tem se mostrado uma ferramenta eficiente para aumentar a visualização e detecção de microcalcificações, uma vez que permite, por meio da combinação de imagens obtidas com energias diferentes (baixa e alta energia), suprimir o ruído estrutural. Por outro lado, pesquisas recentes sugerem que esta técnica permite a obtenção de imagens quantitativas das espessuras de microcalcificações e frações glandulares presentes nos tecidos mamários. O presente trabalho tem como objetivo, o estudo e otimização de imagens quantitativas obtidas através da técnica de mamografia por dupla energia. Este estudo foi realizado por simulação computacional, utilizando o código PENELOPE (Penetrarion and Energy Loss of Positrons and Electrons), o qual foi adaptado para fornecer imagens mamográficas digitais e dados relevantes para o estudo da formação da imagem, bem como fornecer as grandezas dosimétricas de interesse nesta técnica. Para isto, a geometria de um típico exame clínico foi simulado,considerando desde o equipamento mamográfico digital (fonte, placa compressora, suporte e detector), até a mama (pele, gordura, tecidos glandulares e microcalcificações). A validação das adaptações ao código foi feita através da comparação entre os valores de razão espalhado-primário (SPR) e dose glandular normalizada (DgN) gerados neste trabalho, com aqueles presentes na literatura. Finalmente, todos os elementos da 
cadeia da formação de imagens quantitativas foram implementados e avaliados, consistindo de (i) um algoritmo de pré-processamento, que permite corrigir a contribuição do espalhamento nas imagens, com desempenho superior a 95\%; (ii) um algoritmo de pós-processamento nas imagens combinadas (baixa e alta energia) que permite corrigir o aumento do ruído decorrente do pré-processamento e da combinação das imagens, com desempenho de $90 \%$. Os resultados de otimização foram adquiridos para diversas características de mama (espessuras de 2 a $6 \mathrm{~cm}$ e frações glandulares entre 25 e $75 \%$ ) e avaliados para diferentes tamanhos de calcificações. As combinações ótimas de energias (baixa;alta) para mamas com espessuras de 2, 4 e $6 \mathrm{~cm}$ foram $(16 ; 62)$, (19;56) e $(22 ; 56) \mathrm{keV}$, respectivamente. As combinações escolhidas como ótimas conseguiram estimar as espessuras das microcalcificações com exatidão superior a $92 \%$ e a fração glandular com exatidão superior a $95 \%$.

Palavras-chave: 1. Mamografia; 2. Simulação; 3. Dupla-Energia; 4. Quantificação; 5. Otimização. 


\section{Abstract}

GODELI, J. Dual-Energy Digital Mammography: Study and Optimization Using Monte-Carlo Simulation. 2016. 85 f. Dissertation (M.Sc. Postgraduate program in Physics applied to Medicine and Biology) - Faculty of Philosophy, Sciences and Literature, University of São Paulo, Ribeirão Preto - SP, 2016 .

The dual-energy mammography technique has proven to be an efficient tool to increase the visualization and detection of microcalcifications, since it allows, by combining images obtained with different energies (low and high energy), suppress the structural noise. Moreover, recent researches suggests that this technique would allow obtaining quantitative images of microcalcifications thicknesses or glandular fractions present in the breast tissues. This current work aims the study and optimization of quantitative images obtained through dual-energy mammography technique, and was carried out by computer simulation using the PENELOPE code (Penetrarion and Energy Loss of Positron and Electrons), wich was adapted to provide digital mammographic images, and relevant data used in the study of the formation of images and provide the dosimetric quantities of interest in this technique. For this, the model of a typical clinical examination was simulated, from considering the digital mammography equipment (source, compressing plate holder and detector), until the breast (skin, fat, glandular tissues and calcifications). The validation of code adaptation was evaluated by comparing the values of scatter-primary ratio (SPR) and normalized glandular dose (DgN) acquired in this work, with the data in the literature. Finally, all elements of the data chain of the quantitative images were implemented and evaluated, which consist of (i) a 
pre-processing algorithm that corrects the scattering contribution in the images, with a performance superior to $95 \%$; (ii) a post-processing algorithm in the combined images (low and high energy) that allows to correct the increased noise from the pre-processing and from the combination of the images, with a performance of $90 \%$. The optimization results were obtained for different breast characteristics and evaluated in different calcifications sizes. The optimum combinations of energies (low;high) for breasts with thicknesses of 2,4 and $6 \mathrm{~cm}$ were $(16 ; 62),(19 ; 56)$ and $(22 ; 56) \mathrm{keV}$, respectively. The combinations chosen as optimal was able to estimate the thickness of microcalcifications with an accuracy higher than $92 \%$ and the glandular fraction with an accuracy upper to $95 \%$.

Key-words: 1. Mammography; 2. Simulation; 3. Dual-Energy; 4. Quantification; 5. Optimization. 


\section{Lista de Figuras}

1.1 Imagens simuladas em (a) baixa energia (18 keV), (b) alta energia(47 $\mathrm{keV}$ ) e (c) imagem subtraída. Imagem retirada de Bliznakova et al.

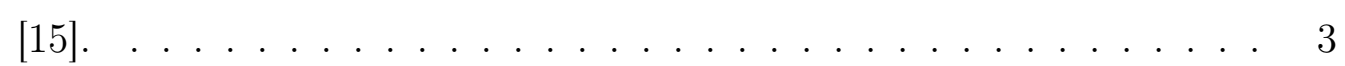

2.1 Esquematização clássica do efeito fotoelétrico. . . . . . . . . . . . 7

2.2 Esquematização clássica do efeito Rayleigh. . . . . . . . . . . . . 8

2.3 Esquematização clássica do efeito Compton. . . . . . . . . . . . . . 9

2.4 Diagrama do processo de formação da imagem radiográfica, considerando a radiação transmitida primária e espalhada. (a) Paciente; (b) Intensidade da radiação transmitida - B1 apenas espalhada e B2 total; (c) Imagem radiográfica. Imagem retirada de Barnes, 1991. . . . . . . . . . . . . . . . . . 12

2.5 Definição de $S C$ em imagens radiográficas, considerando: (a) somente as contribuições de partículas primárias, relacionadas com o tecido circundante e o objeto contrastante, $q_{1_{p}}$ e $q_{2_{p}}$, respectivamente; e (b) a contribuição das radiações primária e espalhada, $q_{1_{p+s}}$ e $q_{2_{p+s}}$. Imagem retirada de Carlson, 1986. . . . . . . . . . . . . . 13

2.6 Mama comprimida de espessura $\mathrm{T}$, com calcificações cúbicas de tamanho $t_{c}$, e tecidos adiposo e glandular de espessuras $t_{a}$ and $t_{b}$, respectivamente, onde $t_{1}+t_{2}=t_{a}+t_{b}$. Imagem retirada de Lemacks et al., 2002. . . . . . . . . . . . . . . . . . 20

3.1 Modelo geométrico utilizado nesta dissertação. . . . . . . . . . . . . 23

3.2 Modelo geométrico da mama. . . . . . . . . . . . . . . . . 24 
$4.1 S P R_{\infty}$ em função da largura de um feixe de $60 \mathrm{keV}$, para fantomas

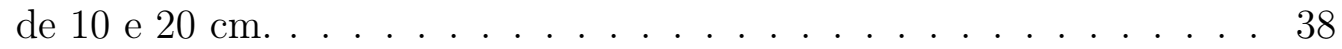

4.2 SPRe de um feixe de $28 \mathrm{kVp}(\mathrm{Mo} / \mathrm{Mo})$ em função da espessura (t) de uma mama . . . . . . . . . . . . . . . . . . . . 39

4.3 DgN em função da energia do feixe monoenergético. Comparação dos valores obtidos com os resultados de Boone, 1999. . . . . . . . . . . . 40

4.4 DgN em função da espessura da mama (t) para os casos de fg de $50 \%$ (a) e $100 \%$ (b) . . . . . . . . . . . . . . . . 4 40

4.5 Número de fótons incidentes no detector. Valores estimados (linha) e adquiridos $($ pontos $) \ldots \ldots \ldots$. . . . . . . . . . . . . 4 41

4.6 Estudo da influência da espessura da mama no contraste (a), ruído (b) e CNR (c) das imagens.

4.7 Estudo da influência da dose total absorvida no contraste (a), ruído (b) e CNR (c) das imagens.

4.8 Imagens adquiridas com número fixo de $4.10^{9}$ fótons e fg de $50 \%$. Considerações para uma mama de $2 \mathrm{~cm}$ irradiadas por um feixe de $20 \mathrm{keV}$ (a) e $50 \mathrm{keV}$ (b) e uma mama de $4 \mathrm{~cm}$ irradiada por um feixe

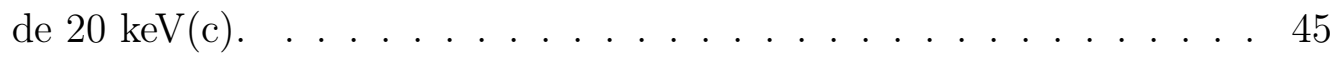

4.9 Imagens geradas a $20 \mathrm{keV}$ ideal (a) e corrigida (b) e $40 \mathrm{keV}$ ideal (c)

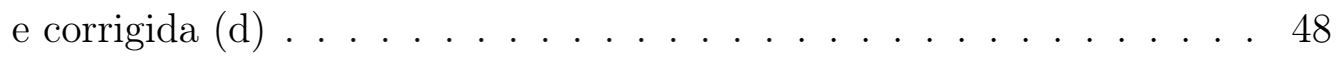

4.10 Imagens tratadas com filtro boxcar (a) e filtro mediana (b) . . . . . . 49

4.11 Combinação entre 16 e $60 \mathrm{keV}$ tratada com o filtro KNR. . . . . . . . 50

4.12 Mapa de exatidão para a estimativa da fração glandular de uma mama de $4 \mathrm{~cm}$, na combinação de diferentes energias. . . . . . . . . . . 51

4.13 Mapas de FOM de calcificações de $600 \mu \mathrm{m}$ para mamas de $2 \mathrm{~cm}(\mathrm{a}), 4$ cm(b) e $6 \mathrm{~cm}$ (c) e calcificações de $300 \mu \mathrm{m}$ para uma mama de $4 \mathrm{~cm}(\mathrm{~d}) .52$

4.14 Mapas de FOM e acurácia da estimativa do diâmetro de calcificações em uma mama de $4 \mathrm{~cm}$ de espessura, para diferentes combinações de energias. . . . . . . . . . . . . . . . . . . 54 


\section{Lista de Tabelas}

3.1 Composição elementar dos tecidos adiposo e mamário. . . . . . . . . 24

4.1 Valores de RMSpe entre a imagens ideais e imagens sem e com correção de espalhamento. . . . . . . . . . . . . . . . . . . . 47 47

4.2 Resultados de otimização (combinação de baixa e alta energias) obtidos neste trabalho e por outros autores. . . . . . . . . . 55 


\section{Sumário}

Lista de Figuras $\quad$ x

Lista de Tabelas xii

1 Introdução 1

2 Fundamentos Teóricos $\quad 6$

2.1 Interação da Radiação com a Matéria . . . . . . . . . . . . . . . . . 6

2.1.1 Efeito Fotoelétrico . . . . . . . . . . . . . . 6

2.1.2 Espalhamento Rayleigh . . . . . . . . . . . . . 7

2.1.3 Efeito Compton . . . . . . . . . . . . . 8

2.1.4 Coeficiente de Atenuação Linear . . . . . . . . . . . . . . . 10

2.1.5 Regra das Misturas . . . . . . . . . . . . . 10

2.1.6 Atenuação Exponencial . . . . . . . . . . . . . . . . 11

2.2 Imagem Radiográfica . . . . . . . . . . . . . . . . . . . . 11

2.2.1 Qualidade da Imagem Radiográfica . . . . . . . . . . . . 12

2.2.2 Razão Contraste-Ruído . . . . . . . . . . . . . . . . . . . 15

2.3 Grandezas Dosimétricas . . . . . . . . . . . . . . . . . . . 16

2.3.1 Kerma ....................... 16

2.3.2 Exposição . . . . . . . . . . . . . . . . 17

2.3.3 Dose Absorvida . . . . . . . . . . . . . . . . . . . . . . . . 17

2.3.3.1 Dose Glandular Média . . . . . . . . . . . . . . 18

2.4 Técnica de Radiografia por Dupla-Energia . . . . . . . . . . . . . . . 19

2.4.1 Decomposição de $\mu \ldots \ldots$. . . . . . . . . . . . . . . . . . . . 19

2.4 .2 Subtração de Imagens . . . . . . . . . . . . . . . . . . . . . 20

2.4.3 Quantificação . . . . . . . . . . . . . . . . 20 
3 Materiais e Métodos $\quad 23$

3.1 Construção do Modelo Geométrico . . . . . . . . . . . . . . . . . . 23

3.1 .1 Modelo da Mama . . . . . . . . . . . . . . . . . . . . . . 24

3.2 Adaptação do Código e Sua Validação . . . . . . . . . . . . . . . . . 25

3.2.1 Separação Entre Feixes Primário e Secundário . . . . . . . . . 25

3.2.2 Cálculo das Grandezas Dosimétricas . . . . . . . . . . . . . 26

3.2 .3 Aquisição de imagens . . . . . . . . . . . . . . . . . . . 28

3.3 Estudo do Contraste, Ruído e Razão Contraste-Ruído . . . . . . . . . . 29

3.4 Processamentos e Combinação das Imagens . . . . . . . . . . . . . . . 29

3.4.1 Pré-Processamento: Correção de Espalhamento . . . . . . . . 30

3.4.2 Algoritmo de Combinação: Estimativas de Calcificações e Frações Glandulares . . . . . . . . . . . . . . 31

3.4 .3 Pós-Processamento: Correção de Ruído . . . . . . . . . . . . . 32

3.4.3.1 Filtro Boxcar . . . . . . . . . . . . . . 32

3.4.3.2 Filtro Mediana . . . . . . . . . . . . . . 32

3.4.3.3 Filtro KNR . . . . . . . . . . . . . . . 33

3.5 Considerações Para Otimização . . . . . . . . . . . . . . . . 34

3.5.1 Estimativa da Fração Glandular . . . . . . . . . . . . . . . 34

3.5.2 Estimativa da Espessura de Microcalcificações . . . . . . . . . 34

3.5.2.1 Figuras de Mérito (FOM) . . . . . . . . . . 34

3.5.2.2 Acurácia das Estimativas . . . . . . . . . . . 35

3.5.3 Escolha das Energias Ótimas . . . . . . . . . . . . 35

4 Resultados e Discussões $\quad 37$

4.1 Modificações e Validação no Código PENELOPE . . . . . . . . . . . 37

$4.1 .1 \quad \mathrm{SPR} \ldots \ldots \ldots \ldots \ldots \ldots$

$4.1 .2 \mathrm{DgN} \ldots \ldots \ldots \ldots \ldots$

4.1 .3 Validação das Imagens . . . . . . . . . . . . . . . . . . 41

4.2 Aquisição de Imagens e Estudos de Contraste, Ruído e Razão Contraste-Ruído (CNR) . . . . . . . . . . . . . . . . 42

4.3 Correção de Espalhamento . . . . . . . . . . . . . . . . . . . 47

4.4 Correção de Ruído e Combinação das Imagens . . . . . . . . . . . . . 48 


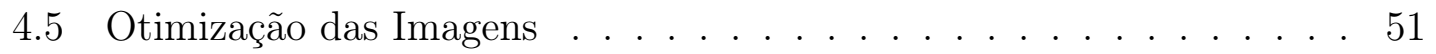

4.5.1 Estimativa de Fração Glandular . . . . . . . . . . . . . . . . 51

4.5.2 Estimativa das Espessuras de Microcalcificações . . . . . . . . 52

4.5.3 Escolha das Energias Ótimas . . . . . . . . . . . . . . . 54

5 Conclusões e Perspectivas Futuras $\quad 57$

5.1 Conclusões . . . . . . . . . . . . . . . . . . . 57

5.1.1 Sobre a utilização do código PENELOPE adaptado e aquisição das imagens. . . . . . . . . . . . . . . . . 57

5.1.2 Sobre a aplicação dos algoritmos de pré-processamento, combinação e pós-processamento . . . . . . . . . . 58

5.1 .3 Sobre a otimização das imagens . . . . . . . . . . . . . . 58

5.1 .4 Sobre as limitações encontradas . . . . . . . . . . . . . . 58

5.2 Perspectivas Futuras . . . . . . . . . . . . . . . . . . . 58

$\begin{array}{ll}\text { Referências Bibliográficas } & 60\end{array}$ 


\section{Capítulo 1}

\section{Introdução}

O câncer afeta aproximadamente 600 mil pessoas no Brasil todos os anos, sendo o câncer de mama, o tipo mais diagnosticado em mulheres [1]. Em 2016, é estimado que aproximadamente 58 mil novas incidências deste tipo de câncer sejam registradas, representando $28,1 \%$ do total de casos entre as mulheres [1]. Em 2013 foram registradas no Brasil, 14.388 mortes devido ao câncer de mama [2], sendo esta, uma taxa de mortalidade alta, já que no Brasil, a doença ainda é diagnosticada em estágios avançados [2]. Porém, nos últimos 40 anos, a sobrevida no país vem aumentando, sendo atualmente de $85 \%$, enquanto outros países emergentes permanecem com valores entre $50 \%$ e $60 \%$ [2].

O diagnóstico precoce do câncer de mama pode ser realizado através da mamografia, pois esta pode detectar a doença em um estágio assintomático, possibilitando tratamentos menos agressivos e aumentando a chance de sobrevida do paciente [3]. Um possível indicativo da formação de tumores malignos, é a presença de microcalficações na mama, bem como sua morfologia. Já a densidade do tecido glandular mamário, pode indicar uma predisposição à doença.

Baker, et al. [4] mostrou que a visualização de calcificações, bem como o estudo de seus tamanhos, formatos e composições, pode servir como indicativo para classificá-las como benignas ou proliferativas, o que pode indicar a presença de tumores malignos como carcinoma ductal invasivo (IDC), ou carcinoma ductal in situ (DCIS).

Já para o caso da densidade mamária (fração glandular), estudos mostram 
que há relação entre o aumento de volume glandular mamário e a incidência de câncer de mama [5, 6]. De acordo com Kuchiki, et. al [7],em um estudo feito com mulheres em pré e pós menopausa, foi notada uma maior incidência de câncer de mama nas pacientes que possuíam um volume maior de tecido glandular. Assim, pode-se dizer que com uma densidade glandular maior, aumenta o risco da formação de tumores malignos.

Um problema comumente encontrado na aplicação da mamografia digital convencional, é sua baixa capacidade de detecção de microcalcificações, devido ao ruído estrutural mamário, proveniente da diferença entre os coeficientes e atenuação dos tecidos que compõem a mama e se sobrepõem às microcalcificações [8, 9]. Além disso, o método de aquisição de imagem convencional possui capacidade limitada de visualizar tecidos glandulares [10]. Uma alternativa para se contornar estes problemas, é a aplicação da técnica de mamografia por dupla energia, que consiste na aquisição e combinação de duas imagens convencionais, sendo uma em alta energia e outra em baixa energia, a fim de realçar alguma característica da mama, ao suprimir o contraste das demais estruturas presentes. Esta técnica se mostrou eficaz para a visualização de microcalcificações e tecidos glandulares $[11,12,13,14,15,16]$. De acordo com Bliznakova, et al. [15], imagens combinadas em dupla-energia possuem uma razão sinal-ruído (SNR) menor que imagens de radiografia convencional, devido a propagação de ruído durante o processo de combinação das imagens. Apesar da ocorrência deste fato, a visualização de microcalcificações dada pela técnica de dupla-energia, é muito superior do que a de uma imagem convencional, devido a supressão do tecido mamário durante a combinação das imagens, enquanto há o aumento da visibilidade e detectabilidade das calcificações.

A figura 1.1, mostra o realce das calcificações proporcionado pela aplicação da técnica de dupla-energia.

Estudos teóricos e experimentais [17, 13, 18, 8, 19] mostraram a eficiência da utilização da técnica de dupla energia para a visualização de microcalcificações, além de apresentar realce da componente glandular em uma imagem mamográfica.

Demais estudos $[14,10,20]$ mostraram que a técnica de dupla energia pode ser utilizada também, nas quantificações da espessura de microcalcificações e fração glandular, o que pode proporcionar um importante avanço para o estudo da formação 


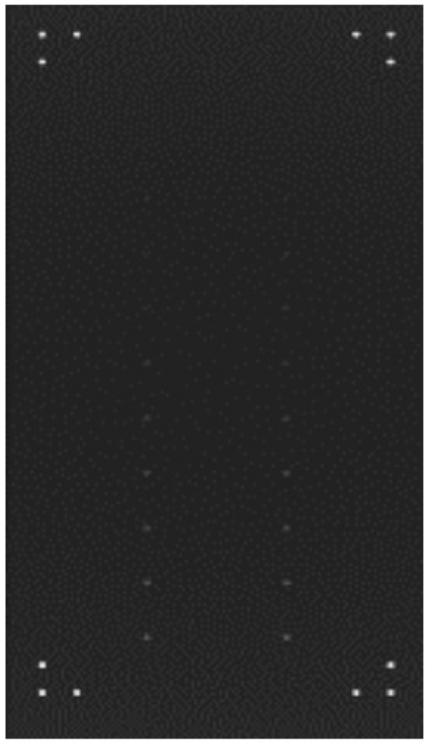

(a)

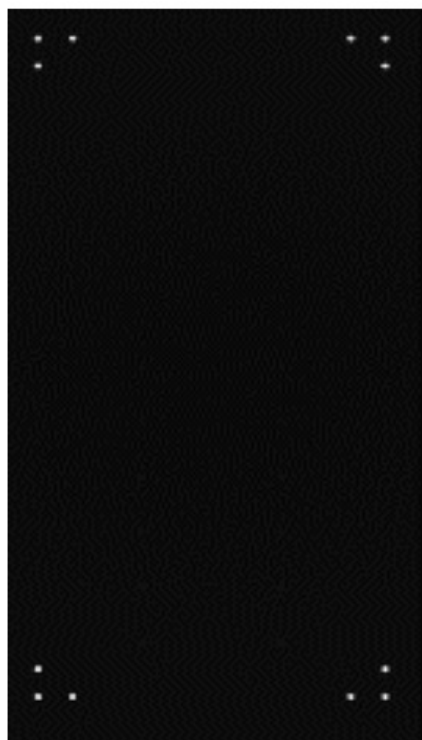

(b)

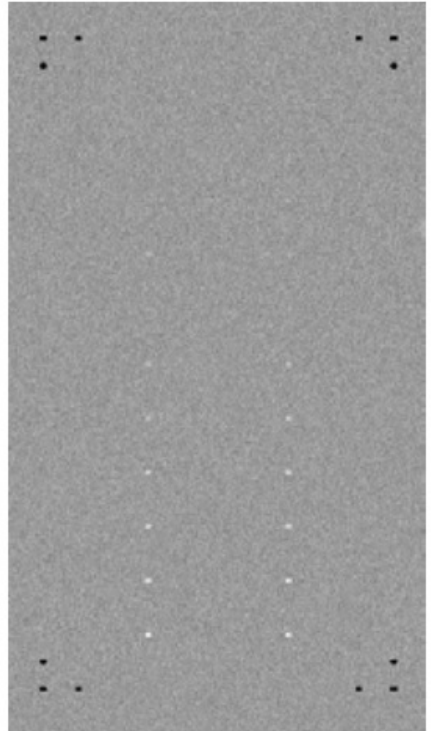

(c)

Figura 1.1: Imagens simuladas em (a) baixa energia (18 keV), (b) alta energia( 47 keV) e (c) imagem subtraída. Imagem retirada de Bliznakova et al. [15].

de tumores e sua prevenção.

A simulação computacional para a realização de estudos radiológicos é utilizada por diversos autores, pois proporciona uma alta flexibilidade no controle do ambiente experimental $[21,22,23,24,25,26]$, possibilitando a aquisição de uma variada rede de dados importantes na condução de diversos estudos, como o controle de qualidade de sistemas radiográficos [22], propriedades da geração de imagens [22, 23, 24] e estudos comparativos de técnicas radiográficas [25].

A técnica de mamografia por dupla energia vem sendo estudada por meio de simulações computacionais, a fim de se buscar a otimização da técnica para a visualização de microcalcificações [15, 27], ou para a quantificação da espessura de calcificações e fração glandular [28, 29].

Geralmente, os trabalhos que envolvem simulação são realizados através de códigos construídos pelos próprios autores [21, 22, 15, 24, 25, 26, 27], porém, estes códigos podem possuir limitações (como por exemplo, considerar apenas o transporte de fótons no meio material), o que pode tornar os dados gerados mais imprecisos. Códigos já conhecidos, como o GEANT4 [30] ou o PENELOPE [31], podem ser adaptados e utilizados para a simulação de sistemas radiográficos, possibilitando 
uma geração de dados mais precisa.

O código de simulação Monte-Carlo PENELOPE (Penetration and Energy Loss of Positrons and Electrons) [31] foi desenvolvido para simular as interações das radiações ionizantes (elétrons, pósitrons e raios X) com a matéria usando uma base de dados atualizada, abrangendo energias entre 50 e $10^{9} \mathrm{eV}$, podendo assim, ser facilmente aplicado na área de mamografia.

Neste trabalho, o código PENELOPE foi utilizado para simular imagens mamográficas, a fim de se aplicar a técnica de dupla energia na geração de imagens quantitativas, para a verificação da morfologia de microcalcificações e da fração glandular, visando o estudo da otimização desta técnica para tal fim.

Os principais objetivos deste trabalho foram:

1. Adaptar e validar o código PENELOPE para utilizá-lo na simulação de imagens de mamografia digital;

2. Implementar algoritmos de pré-processamento nas imagens geradas;

3. Aplicar um algoritmo de combinação e pós-processamento nas imagens adquiridas;

4. Estudar a técnica de dupla energia, a fim de obter as combinações de qualidades de feixes que otimizem as estimativas da espessura de microcalcificações e taxa glandular presentes, levando em consideração a dose que foi absorvida pela mama.

Esta dissertação é apresentada em cinco capítulos.

Após esta introdução, no capítulo 2 são apresentados os embasamentos teóricos para os estudos realizados neste trabalho. São apresentados os fundamentos que envolvem a interação da radiação com a matéria, levando em consideração o intervalo de energia da radiação utilizado neste trabalho (radiodiagnóstico). São apresentados os efeitos fotoelétrico e os espalhamentos coerente e incoerente. Após isso, foi apresentada a definição do coeficiente de atenuação linear da matéria (homogênea ou mistura). A seguir, são apontadas as grandezas dosimétricas 
de interesse do trabalho, como exposição e dose glandular normalizada. São apresentados também, conceitos de formação de imagens de radiodiagnóstico, com a definição de contraste e ruído. Por fim, são mostrados os princípios da formação da imagem pela técnica de dupla energia, sobre a qual, este trabalho se sustenta.

A metodologia seguida para a realização do projeto está detalhada no capítulo 3. Primeiramente, realiza-se a descrição do modelo geométrico construido para a geração das imagens. A seguir, são descritas as adaptações realizadas no código PENELOPE para esta finalidade, bem como as adaptações necessárias para a simulação dos estudos já existentes na literatura, que foram utilizadas na validação do código adaptado. Na próxima etapa, são descritos os algoritmos de pré-processamento, combinação e pós-processamento, utilizados nas imagens quantificadas. Por fim, são apresentados os passos tomados para a escolha das imagens otimizadas.

No capítulo 4 são apresentados os resultados obtidos. A validação do código é o primeiro resultado apresentado, seguido das imagens geradas. As imagens pré-processadas são mostradas e comparadas com os resultados sem processamento, a fim de se destacar a importância de seu uso. A seguir, a escolha e aplicação do algoritmo de pós-processamento (para correção de ruído) é mostrada. Finalmente, as combinações otimizadas de baixa e alta energias, são definidos com base em parâmetros específicos.

O capítulo 5, abrange as conclusões alcançadas nas discussões dos resultados obtidos e as perspectivas de futuros trabalhos que podem ser realizados como continuação deste trabalho. 


\section{Capítulo 2}

\section{Fundamentos Teóricos}

\subsection{Interação da Radiação com a Matéria}

As interações da radiação eletromagnética ionizante de baixa energia $(\mathrm{E}<2$ $\mathrm{MeV}$ ) com a matéria, são classificadas em quatro tipos: Efeito fotoelétrico, espalhamento Rayleigh, Efeito Compton e produção de pares. Este ultimo, ocorre apenas para energias com fótons acima de $1,02 \mathrm{MeV}$ [32], fora da faixa de energia de mamografia convencional, que corresponde à uma faixa no intervalo entre 8 e $35 \mathrm{keV}$ $[33,34]$, se tornando então, irrelevante para o presente trabalho. Os três tipos de interações considerados serão descritos a seguir.

\subsubsection{Efeito Fotoelétrico}

O efeito fotoelétrico consiste na ejeção de um elétron orbital, após a transferência total da energia de um fóton para o átomo. A energia de ejeção (T) é dada por $T=h \nu-E_{b}$, onde $E_{b}$, é a energia de ligação do elétron e sua camada orbital e $h \nu$, a energia do fóton incidente. O efeito é ilustrado na figura 2.1.

Após a interação, há uma liberação de raio X característico, ou elétron Auger no processo de ocupação da vacância deixada pelo elétron ejetado [35, 36].

A proporcionalidade da seção de choque atômica para o efeito fotoelétrico $(\tau)$, em relação ao número atômico $\mathrm{Z}$ e a energia do fóton $h \nu$ dada por [35]:

$$
\tau \propto \frac{Z^{4}}{(h \nu)^{3}}
$$

Onde, $\tau$ possui unidades de $\mathrm{cm}^{2} /$ átomo. A probabilidade da ocorrência do efeito fotoelétrico, $\tau$, é predominante em baixas energias e em materiais de altos números 


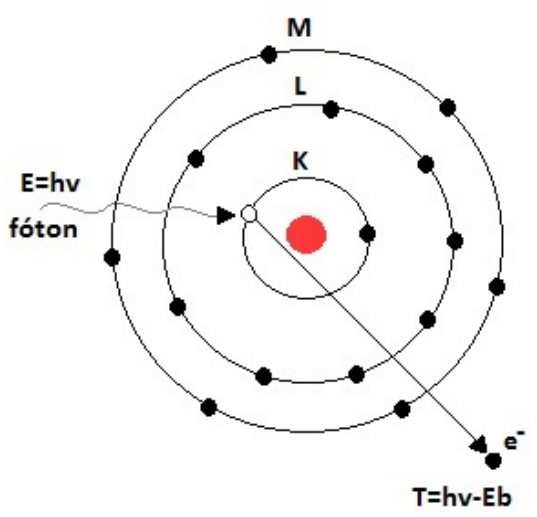

Figura 2.1: Esquematização clássica do efeito fotoelétrico.

atômicos, de acordo com a equação 2.1 .

\subsubsection{Espalhamento Rayleigh}

O espalhamento Rayleigh, também chamado de espalhamento coerente ou elástico, ocorre quando um fóton interage com a matéria, mudando sua trajetória, porém, sua energia não é modificada. Descrevendo de forma mais detalhada, quando um fóton interage com a matéria, o campo elétrico associado a ele (onda eletromagnética, com comprimento $\lambda$ ), origina uma vibração nos elétrons desta matéria. A aceleração destas partículas carregadas, gera um fóton (onda eletromagnética) com o mesmo comprimento de onda, $\lambda$ [37]. O efeito é ilustrado na figura 2.2.

A distribuição angular dos fótons elasticamente espalhados em um material é dada pela seção de choque diferencial, $(\mathrm{d} \sigma / \mathrm{d} d \Omega)^{e l}$.

$$
\left(\frac{d \sigma}{d \Omega}\right)^{e l}=F^{2}(x)\left(\frac{d \sigma}{d \Omega}\right)_{T h}
$$

Sendo $\mathrm{F}(\mathrm{x})$, o fator de forma do meio, proposto por Hubbell et al. [38]. Este fator é dado em função de uma grandeza (x) proporcional ao momento transferido, dada por: $x=\lambda^{-1} \operatorname{sen}(\theta / 2)$, sendo $\lambda$, o comprimento da onda do fóton e $\theta$, o ângulo 


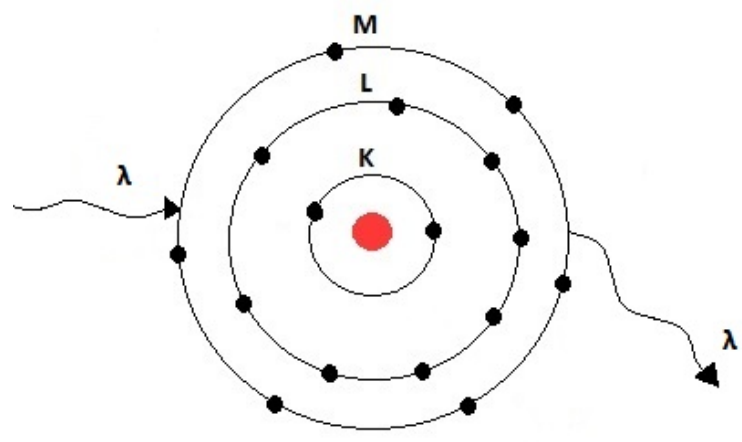

Figura 2.2: Esquematização clássica do efeito Rayleigh.

polar de espalhamento. O termo $(d \sigma / d \Omega)_{T h}$ é a seção de choque diferencial Thomson para o espalhamento de um elétron livre [37].

A seção de choque total (Rayleigh), $\sigma_{r}$, possui uma proporcionalidade com o número atômico de um material puro e energia do fóton, por [35]:

$$
\sigma_{r} \propto \frac{Z^{2}}{(h \nu)^{2}}
$$

Onde, $\sigma_{r}$, possui unidades de $\mathrm{cm}^{2} /$ átomo. Essa proporcionalidade indica que este efeito tem maior ocorrência para feixes de baixas energias e materiais de maior número atômico, porém, ocorrem em menor frequência que o efeito fotoelétrico.

\subsubsection{Efeito Compton}

O efeito Compton, também chamado de espalhamento incoerente ou inelástico, ocorre quando um fóton interage com a matéria desvia-se de sua trajetória original por um ângulo $\theta$, transferindo parte de sua energia para os elétrons do meio na forma de energia cinética, como ilustrado na figura 2.3. Este efeito foi estudado inicialmente por Compton, que tratou a radiação eletromagnética como pacotes de ondas quantizados com energia $h \nu$ [37].

As energias do fóton $\left(h \nu^{\prime}\right)$ e do elétron $(T)$ espalhados são dados pelas 


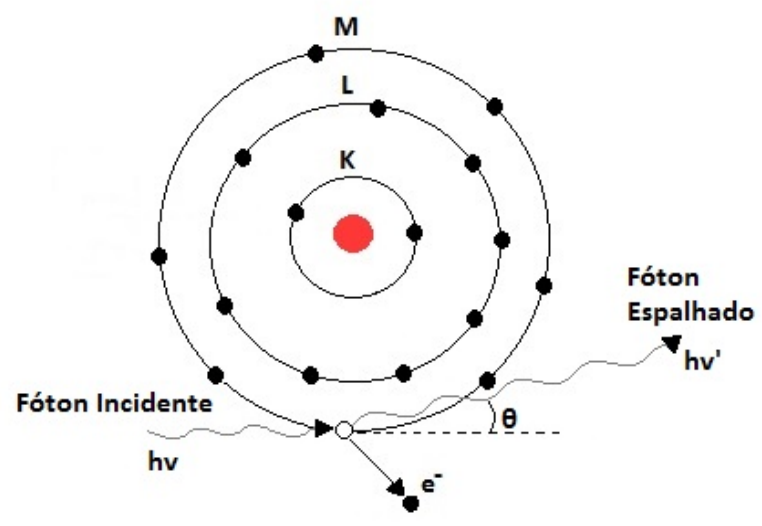

Figura 2.3: Esquematização clássica do efeito Compton.

equações 2.4 e 2.5 , respectivamente [39].

$$
\begin{aligned}
h \nu^{\prime} & =h \nu \times \frac{1}{1+\alpha(1-\cos \theta)} \\
T & =h \nu \times \frac{\alpha(1-\cos \theta)}{1+\alpha(1-\cos \theta)}
\end{aligned}
$$

Sendo, $\alpha=h \nu / m_{0} c^{2}$, onde $m_{0} c^{2}$, corresponde à energia de repouso do elétron $(0,511 \mathrm{MeV})$.

O espalhamento inelástico para um átomo (ou molécula) pode ser descrito a partir de uma aproximação análoga à utilizada para o espalhamento elástico, utilizando agora um fator $S(x)$, chamado de função de espalhamento inelástico [38], a seção de choque para este processo pode ser escrita como:

$$
\left(\frac{d \sigma}{d \Omega}\right)_{\text {inel }}=S(x)\left(\frac{d \sigma}{d \Omega}\right)_{K N}
$$

Onde, $(\mathrm{d} \sigma / \mathrm{d} d \Omega)_{K N}$ descreve a seção de choque diferencial Klein-Nishina para o elétron livre [35]. Considerando um material puro, a seção de choque total para o espalhamento inelástico por átomo $\sigma_{c}$ é proporcional ao número atômico Z e aumenta suavemente com a energia dos fótons deste trabalho (16-80keV) [40]. 


\subsubsection{Coeficiente de Atenuação Linear}

A seção de choque atômica total $\sigma_{T}$ indica a probabilidade da ocorrência de uma interação qualquer de um fóton com a matéria e é dada pela soma das seções dos processos individuais citados acima, podendo ser escrita como:

$$
\sigma_{T}=\tau+\sigma_{r}+\sigma_{c}
$$

O coeficiente de atenuação linear $(\mu)$ está relacionado com a seção de choque total e com o número de átomos (ou moléculas) por unidade de volume $\left(n_{v}\right)$, através da seguinte equação [35, 40]:

$$
\mu=n_{v} \sigma_{T}
$$

O coeficiente de atenuação linear depende do estado físico ou fase do material, $n_{v}$ é função da densidade do material. Dessa forma, ao se dividir o coeficiente de atenuação linear pela densidade do material $(\rho)$, se define o coeficiente de atenuação mássico. Esta grandeza independe do estado físico do material [37].

O coeficiente de atenuação mássico, está relacionado com a seção de choque total por átomo $\sigma_{T}$ e com a seção de choque total por elétron ${ }^{e} \sigma_{T}$ por:

$$
\frac{\mu}{\rho}=\sigma_{T}\left(\frac{N_{A}}{A}\right)={ }^{e} \sigma_{T}\left(N_{A} \frac{Z}{A}\right)
$$

Sendo $N_{A}$ o número de Avogadro, A o peso atômico do elemento que compõe o material e $N_{A}(\mathrm{Z} / \mathrm{A})$ o número de elétrons por grama do material.

\subsubsection{Regra das Misturas}

A regra das misturas permite obter o coeficiente de atenuação mássico de uma mistura com composição química conhecida, a partir dos coeficientes de atenuação mássico, $(\mu / \rho)_{i}$, tabulados para cada elemento que compõe o material e de sua abundância. Quando a fórmula química é conhecida, o coeficiente de atenuação mássico pode ser calculado pela sua fração de massa $\left(w_{i}\right)$ e pelos $(\mu / \rho)_{i}[35]$ :

$$
\left(\frac{\mu}{\rho}\right)_{\text {mistura }}=\sum_{i} w_{i}\left(\frac{\mu}{\rho}\right)_{i}
$$


A equação 2.10 é conhecida como regra das misturas, a qual fornece um meio de se obter valores dos coeficientes de atenuação para diversos compostos químicos e serve como uma boa aproximação para descrever a interação da radiação com estes compostos. Entretanto, a regra das misturas é uma aproximação que ignora qualquer efeito de mudança ma função de onda do átomo como resultado do arranjo molecular, químico e cristalino [41].

\subsubsection{Atenuação Exponencial}

Quando um feixe de fótons incide sobre um material de espessura $x$, parte é absorvida, parte é espalhada e uma fração é transmitida, ou seja, atravessa o material sem interagir. A intensidade $I$ do feixe transmitido está associada à intensidade $I_{0}$ do feixe incidente, de acordo com a seguinte equação:

$$
I=I_{0} \cdot e^{-\mu x}
$$

A equação acima, descreve a lei de atenuação exponencial, conhecida como Lei de Lambert-Beer [37].

\subsection{Imagem Radiográfica}

Quando um feixe de raios X incide sobre qualquer material, interações podem ocorrer entre a radiação incidente e a matéria, removendo parte da energia do feixe de radiação por absorção ou espalhamento [42]. A da radiação transmitida sem interação (primária), carrega informações sobre o material na forma de uma distribuição espacial de intensidades, perpendicular ao eixo do feixe, responsável pelo contraste primário [43].

Outra parte da radiação transmitida pelo objeto, desta vez proveniente de fótons que interagem (principalmente por espalhamento), conhecidos como radiação secundária, pode atingir o receptor da imagem [37]. A radiação secundária também atua na formação da imagem, adicionando um "background"quase constante ao longo da distribuição espacial dos fótons transmitidos primários. Este processo faz com que o receptor sofra uma maior exposição, degradando o contraste da imagem [43]. 
A figura 2.4 ilustra as contribuições dos feixes primário e espalhado na formação da imagem radiográfica

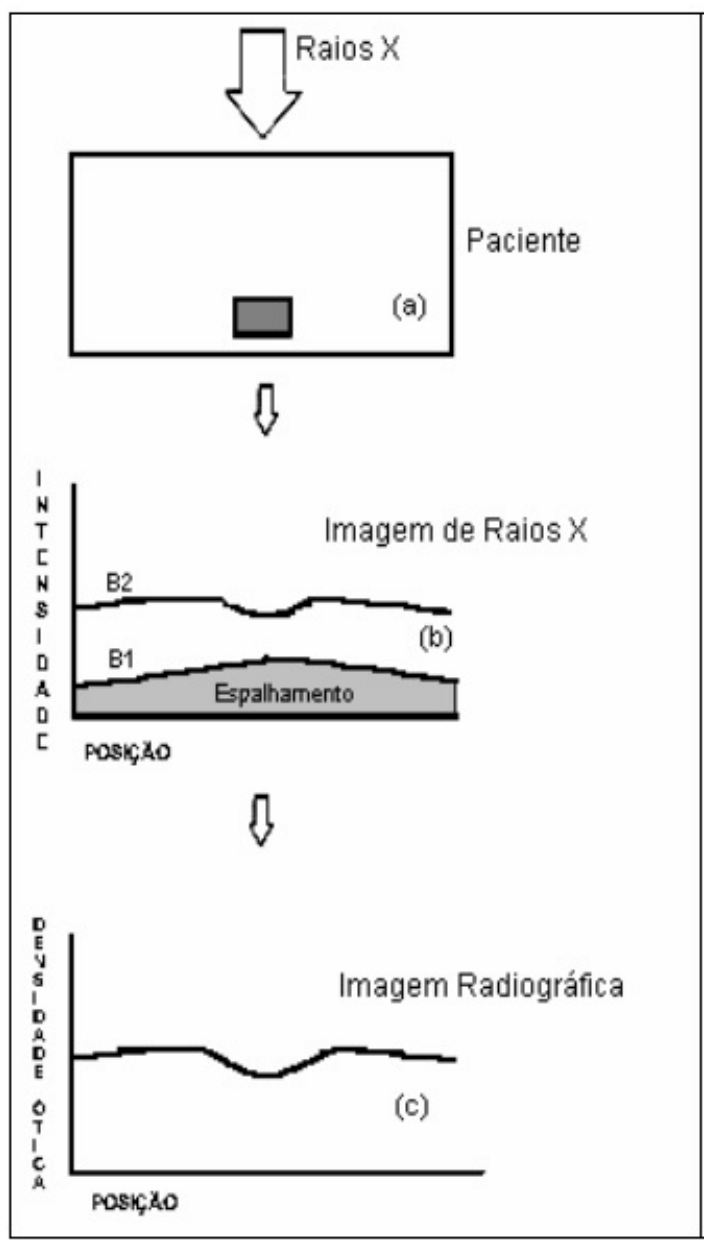

Figura 2.4: Diagrama do processo de formação da imagem radiográfica, considerando a radiação transmitida primária e espalhada. (a) Paciente; (b) Intensidade da radiação transmitida - B1 apenas espalhada e B2 total; (c) Imagem radiográfica. Imagem retirada de Barnes, 1991.

\subsubsection{Qualidade da Imagem Radiográfica}

O contraste em uma imagem radiográfica é o resultado de diferentes etapas que ocorrem durante a aquisição, processamento e visualização das imagens. Diferentes definições de contraste são empregadas para descrever cada etapa da formação da imagem, como descrito a seguir. 


\section{Contraste Objeto}

O contraste objeto, do inglês subject contrast $(S C)$, reflete as diferenças entre as propriedades do objeto e do meio circundante, tais como densidade, composição química e coeficiente de atenuação linear, estando também, relacionado às suas dimensões e as características do espectro de raios X utilizado (material do ânodo, filtração, potencial do tubo e camada semi-redutora) [42].

A figura 2.5 ilustra a definição de $S C$, considerando um corpo e espessura $L$ e um objeto de espessura $x$.
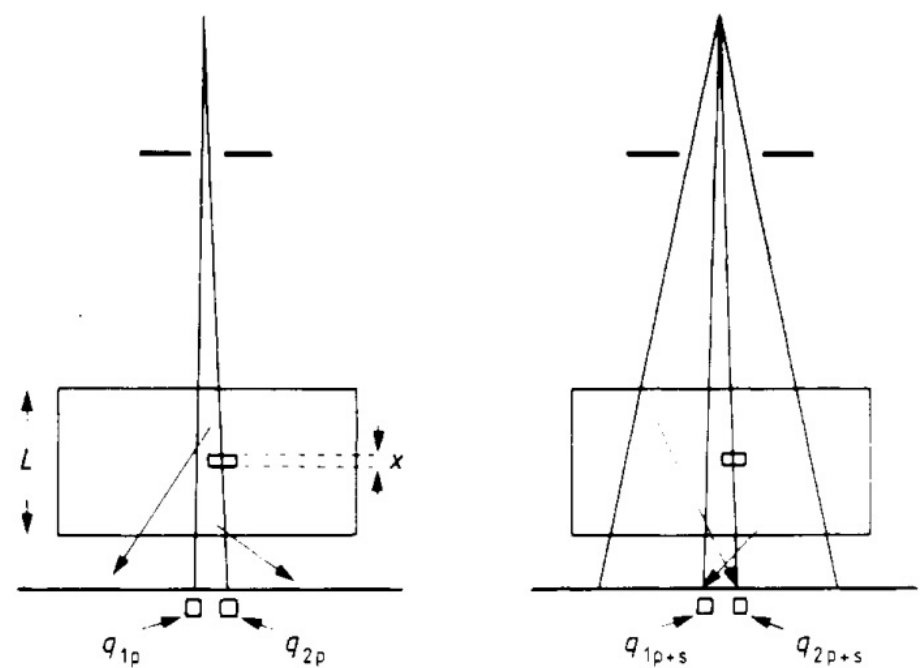

Figura 2.5: Definição de SC em imagens radiográficas, considerando: (a) somente as contribuições de partículas primárias, relacionadas com o tecido circundante e o objeto contrastante, $q_{1_{p}}$ e $q_{2_{p}}$, respectivamente; e (b) a contribuição das radiações primária e espalhada, $q_{1_{p+s}}$ e $q_{2_{p+s}}$. Imagem retirada de Carlson, 1986 .

A figura 2.5(a) mostra o caso em que somente os fótons primários são considerados ao atingirem o receptor (caso ideal), enquanto a figura 2.5(b) mostra a influência tanto do feixe primário quanto do feixe espalhado, na formação da imagem (caso real).

O $S C$ pode ser definido a partir das seguintes relações: 


$$
\begin{gathered}
S C=\ln \left(\frac{q_{1}}{q_{2}}\right) \\
S C=2 \frac{\left|q_{1}-q_{2}\right|}{q_{1}+q_{2}}
\end{gathered}
$$

As grandezas $q_{1}$ e $q_{2}$ representam as fluências de energia absorvidas no receptor de imagem, relacionadas ao tecido circundante e ao objeto contrastante, respectivamente [44] e incluem as contribuições dos fótons primários e espalhados. Com isso, se pode dizer que a eficiência do receptor da imagem influencia no contraste objeto.

Embora as equações 2.12 e 2.13 forneçam resultados similares, a primeira é comumente utilizada para descrever o contraste em um sistema tela-filme, enquanto a segunda é empregada em receptores digitais [44].

Caso os valores de $q_{1}$ e $q_{2}$ sejam próximos, a equação 2.13 pode ser aproximada por:

$$
S C=\frac{\left|q_{1}-q_{2}\right|}{q_{1}}
$$

Segundo Carlsson et al [44], a grandeza física mais apropriada para q, é a fluência de energia absorvida no receptor de imagem, embora existam outras definições apresentadas na literatura [45, 46, 43, 47].

\section{Degradação do Contraste por Espalhamento}

Em uma situação real, como mostrada na figura 2.5(b), a fluência de fótons chegando ao receptor de imagem, contém contribuições de fótons primários $q_{p} \mathrm{e}$ espalhados $q_{s}$. Considerando que $q_{2}=q$ e $q_{1}=q+\Delta q$, sendo $q=q_{p}+q_{s}$ e assumindo que a radiação é uniforme no receptor da imagem $\left(q_{1 s}=q_{2 s}=q_{s}\right)$, o contraste do objeto, apresentado na equação 2.12 pode ser reescrito como:

$$
S C=\ln \left(1+\frac{\Delta q_{p}}{q_{p}+q_{s}}\right)=\ln \left(1+C D F \cdot \frac{\Delta q_{p}}{q_{p}}\right)
$$

Onde $C D F$ é o fator de degradação do contraste, sendo escrito como:

$$
C D F=\left(1+\frac{q_{s}}{q_{p}}\right)^{-1}
$$


Para valores muito pequenos, o $S C$ pode ser calculado considerando a contribuição dos fótons espalhados através da equação:

$$
S C=C D F \cdot \frac{\Delta q_{p}}{q_{p}}
$$

O mesmo resultado pode ser deduzido, usando a equação 2.13.

Os valores de $q_{s} / q_{p}=S / P$ podem ser utilizados para quantificar o efeito do espalhamento no contraste do objeto em exames mamográficos. Este termo é chamado de razão espalhado-primário. A intensidade relativa da radiação espalhada varia com a espessura e composição da mama, tamanho de campo, atenuação e a energia da radiação incidente. Valores típicos na mamografia encontram-se no intervalo de 0,33 a 1,5 [48].

\subsubsection{Razão Contraste-Ruído}

Após a obtenção da imagem por um sistema de detecção digital, ela é pré-processada automaticamente pelo software de aquisição através de uma série de etapas. Assim, uma vez que o contraste na imagem pode ser fortemente alterado, ele não é considerado o parâmetro de qualidade mais significativo para a descrição de uma imagem digital.

O parâmetro de qualidade de imagem mais utilizado em aquisições digitais é a razão contraste-ruído $(C N R)$, descrita na equação a seguir:

$$
C N R=\frac{\left|q_{2}-q_{1}\right|}{\sigma}
$$

Sendo o termo $\sigma$, a incerteza do sinal mensurado.

A $C N R$ não é afetada por processamentos da imagem, sendo portanto, uma grandeza mais relevante para descrever a visualização de diferentes estruturas em uma imagem digital [49]. De forma análoga ao contraste, a $C N R$ depende das propriedades do objeto e da vizinhança, das características do feixe incidente e do receptor de imagem utilizado [50, 49]. 


\subsection{Grandezas Dosimétricas}

Para descrever a conversão e deposição de energia na matéria, torna-se útil definir grandezas não-estocásticas, chamadas de grandezas dosimétricas. Estas representam as medidas dos processos pelos quais a energia de uma partícula é convertida ou depositada na matéria. Nesta seção são descritas as principais grandezas dosimétricas de interesse em mamografia.

\subsubsection{Kerma}

A grandeza dosimetrica chamada Kerma (Kinect Energy Released per unit MAss) é definida em termos da energia transferida de uma partícula não carregada para partículas carregadas como energia cinética, por unidade de massa, em um ponto de interesse, incluindo a energia de perdas radioativas e excluindo a energia transferida de uma partícula carregada para outra [35]. O kerma $(K)$ é definido como:

$$
K=\frac{d \bar{E}_{t r}}{d m} \quad\left[\text { unidade }: \frac{J}{k g}=G y\right]
$$

onde $d \bar{E}_{t r}$ é o valor médio da energia transferida por partículas não-carregadas, para partículas carregadas com energia cinética, em um volume infinitesimal de massa $d m$.

Para um feixe polienergetico incidindo em um ponto $\mathrm{P}$, o kerma pode ser definido como mostrado na equação a seguir.

$$
K=\int_{E=0}^{E_{\max }} E \times \Phi_{E}(E) \times\left(\frac{\mu_{t r}}{\rho}(E)\right) d E
$$

Sendo $\mu_{t r} / \rho$, o coeficiente de transferência de energia mássico e $\Phi_{E}(E)$, a fluência incidente com energia entre $E$ e $E+d E$. 


\subsubsection{Exposição}

A exposição $(X)$ descreve um campo de raios X com base em sua capacidade de ionizar o ar. Esta grandeza é definida de acordo com a equação a seguir:

$$
X=\frac{d Q}{d m} \quad\left[\text { unidade }: \frac{C}{k g}\right]
$$

Onde $d Q$ representa o valor, em coulomb, carga total de íons de mesmo sinal produzidos no ar, quando todos os elétrons liberados por fótons em uma massa $d m$ de ar, são completamente freados neste meio [35].

A exposição em um ponto $P$ pode ser relacionada ao kerma no ar neste mesmo ponto, de acordo com a seguinte equação:

$$
X=(1-g)\left(\frac{e}{\bar{W}}\right) K_{a r}
$$

sendo $g$, a fração da energia perdida pelo elétron na produção de raio-X, $\bar{W}$ é a energia média gasta em um gás para se produzir um par de íons e por fim, e é a carga do elétron. Para o ar, $\bar{W} / e=33,97 \mathrm{~J} / \mathrm{C}[35]$.

Para partículas carregadas não relativísticas, $g \approx 0$. Com esta consideração, a relação entre exposição e kerma no ar, mostrada na equação 2.22 , é simplificada.

\subsubsection{Dose Absorvida}

A dose absorvida é uma grandeza dosimétrica de grande interesse na física radiológica e se relaciona com a energia absorvida no meio. Em um ponto $P$, a dose absorvida é definida como:

$$
D=\frac{d \bar{E}_{a b}}{d m} \quad[\text { unidade }: G y]
$$

A dose absorvida está relacionada diretamente com as partículas carregadas secundárias geradas no meio irradiado [35]. Em um caso geral, não é possível descrever a dose com uma relação simples em função da fluência de energia. Somente na condição de equilíbrio de partículas carregadas (EPC), a dose absorvida em um meio se aproxima do kerma colisional no ar e pode ser descrito a partir de parâmetros relacionados ao feixe incidente e ao meio irradiado [35]. 
Para um material de uma determinada espessura, a dose absorvida depende da profundidade do material analisado, uma vez que o feixe incidente é atenuado pelo meio de forma que alguns fótons podem ser absorvidos ou espalhados e as partículas carregadas podem transferir energia em diferentes profundidades [35]. Assim, a dose média absorvida no material, é obtida ao se integrar toda sua espessura $L$.

$$
\bar{D}=\frac{1}{L} \int_{z=0}^{z=L} D(z) d z
$$

Sendo $D(z)$, a dose absorvida em uma camada na profundidade $z$. Este termo depende da fluência de fótons naquela camada, na condição de EPC. Lembrando que a fluência de fótons em qualquer profundidade, é composta tanto de fótons primários como secundários (espalhados).

\subsubsection{Dose Glandular Média}

A dose glandular média $\left(\bar{D}_{g}\right)$ é considerada a grandeza dosimétrica mais adequada para descrever o risco de carcinogênese associado ao exame mamográfico, uma vez que o tecido glandular é considerado o mais sensível à radiação ionizante $[51,52,53]$. Como a medida direta desta grandeza é impossível [53], diversos modelos para sua determinação foram propostos, buscando relacionar fatores de conversão com a medida do kerma no ar na entrada da mama [52, 54, 55, 53].

O modelo mais simples para a determinação da $\bar{D}_{g}$ em mamografia, relaciona esta grandeza com a medida do kerma de entrada na mama, utilizando apenas um parâmetro, conforme mostrado na equação a seguir $[52,55,56,57]$ :

$$
\bar{D}_{g}=K_{a r} \cdot \bar{D}_{g N}
$$

sendo $\bar{D}_{g N}$, um fator chamado de dose glandular normalizada, que representa a razão entre a dose média absorvida no tecido glandular e o kerma no ar de entrada na mama, sem retroespalhamento. Este modelo de determinação de $\bar{D}_{g}$ foi proposto por Stanton et al. [52] e Wu et al. [55, 58], sendo recomendado pelo Protocolo Americano de Dosimetria [59]. Entretanto, os autores utilizaram um fator de conversão para a medida de exposição na entrada da mama.

A dose glandular normalizada depende exclusivamente das características físicas da mama (espessura e glandularidade) e da radiação incidente (combinação 
ânodo/filtro, potencial do tubo e camada semi-redutora).

Um modelo alternativo para a determinação $\bar{D} g$ foi proposto por Dance [54] e modificado em trabalhos posteriores [60, 53], sendo recomendado no Protocolo Europeu de Dosimetria [61]. Neste modelo, a $\bar{D}_{g N}$ é fatorizada em três diferentes grandezas: $g, c$ e $s$, utilizadas para descrever as dependências com a espessura da mama e $C S R$, composição da mama e combinação ânodo/fitro, respectivamente. Assim, a $\bar{D}_{g}$ pode ser determinada a partir da seguinte relação;

$$
\bar{D}_{g}=K_{a r} . g . c . s
$$

De forma geral, a determinação de $\bar{D}_{g}$ de acordo com as equações 2.25 e 2.26, é baseada somente na determinação dos fatores de dose glandular normalizada, uma vez que o kerma no ar de entrada na pele pode ser determinado ao se utilizar uma câmara de ionização $[62,63]$.

Apesar da normalização através do Kerma no ar ser a mais utilizada, alguns autores consideram a normalização da dose através da exposição na entrada da pele $\left(X_{e}\right)$ como a mais prática para se computar a dose em uma mamografia $[49,64]$.

\subsection{Técnica de Radiografia por Dupla-Energia}

A mamografia digital por dupla-energia é uma técnica que explora a diferença entre os coeficientes de atenuação de diferentes componentes da mama, a partir da combinação entre duas aquisições mamográficas convencionais obtidas com baixa e alta energias [17, 18, 65], podendo ser aplicada através de diversas formas:

\subsubsection{Decomposição de $\mu$}

Esta técnica foi proposta por Alvarez e Macovski [66] e se baseia na idéia de que o coeficiente de atenuação linear de um material, para determinada energia, pode ser descrito como a combinação linear de duas funções dependentes da energia e dois fatores de ponderação, específicos do material analisado. Lehmann et al. [67], propôs que o coeficiente de atenuação linear de um material qualquer, pode ser decomposto em dois coeficientes de atenuação de dois materiais base (como por 
exemplo, lucite e alumínio), multiplicados por suas respectivas espessuras. Com isso, a partir de aquisições de imagens em energias diferentes, é possível se determinar o coeficiente de atenuação de qualquer material, possibilitando a obtenção de imagens radiográficas que destaquem algum determinado tecido de interesse.

\subsubsection{Subtração de Imagens}

Esse método permite realçar um tecido de interesse, a partir da subtração ponderada entre imagens mamográficas convencionais, ao se suprimir o sinal do background de seu entorno. Estudos mostraram que a técnica de mamografia por subtração em dupla-energia pode ser capaz de detectar calcificações com maior eficiência, se comparada à aquisição convencional [68, 13, 69, 70, 18, 15].

\subsubsection{Quantificação}

A técnica de dupla energia, além de realçar determinado tecido, pode ser aplicada em mamografia nas quantificações da espessura de calcificações e fração glandular. O algoritmo de combinação das imagens se baseia nos estudos realizados por Lemacks et al. [14].

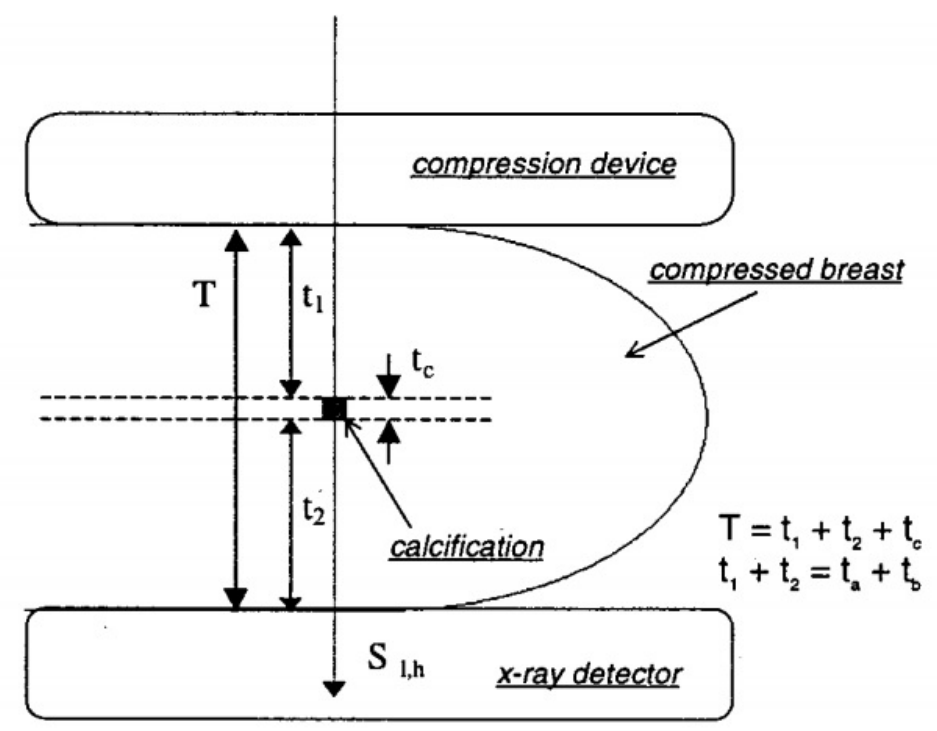

Figura 2.6: Mama comprimida de espessura $T$, com calcificações cúbicas de tamanho $t_{c}$, e tecidos adiposo e glandular de espessuras $t_{a}$ and $t_{b}$, respectivamente, onde $t_{1}+t_{2}=t_{a}+t_{b}$. Imagem retirada de Lemacks et al., 2002. 
Considerando uma mama com espessura total $\mathrm{T}$, como mostrada na figura 2.6, composta por tecidos adiposo e glandular com espessuras ta e tb, respectivamente, pode-se considerar a seguinte relação:

$$
T=t_{a}+t_{b}+t_{c}
$$

Sendo $t_{c}$, a espessura da calcificação presente na mama.

Considerando um feixe monoenergético com energia E e uma fluência de partículas $\Phi$ que atravessa a região contendo a calcificação, e o sinal de fótons transmitidos primários, é dado pela seguinte equação:

$$
S=\Phi(E) \times e^{-\mu_{a} \cdot t_{a}} \times e^{-\mu_{b} \cdot t_{b}} \times e^{-\mu_{c} \cdot t_{c}}
$$

Sendo, $\mu_{a}, \mu_{b}$ e $\mu_{c}$, os coeficientes de atenuação lineares dos tecidos adiposo, glandular e de calcificação, respectivamente. Se isolarmos o termo $t_{a}$ da equação 2.27 e aplicarmos em 2.28, temos:

$$
S=\Phi(E) \times e^{-\mu_{a} \cdot T} \times e^{-\Delta \mu_{b} \cdot t_{b}} \times e^{-\Delta \mu_{c} \cdot t_{c}}
$$

Definindo $\Delta \mu_{b} \equiv \mu_{b}-\mu_{a}$ e $\Delta \mu_{c} \equiv \mu_{c}-\mu_{a}$. De acordo com Lemacks et al. [14], as análises devem ser realizadas levando em consideração, apenas as calcificações e o tecido glandular. Para se cancelar a dependência do tecido adiposo, é necessária a aquisição de uma imagem de referência, gerada por uma mama contendo apenas este tecido, com sua espessura $t_{a}$, igual à $T$. Na imagem de referência, o sinal transmitido primário pode ser escrito por:

$$
S_{a}=\Phi(E) \times e^{-\mu_{a} \cdot T}
$$

Definido um termo $D=F\left(t_{b}, t_{c}\right)$, como uma relação entre os sinais dados por 2.29 e 2.30, análoga à densidade ótica, dada por:

$$
D=\ln \left(\frac{S_{a}}{S}\right)=\Delta \mu_{b} \cdot t_{b}+\Delta \mu_{c} \cdot t_{c}
$$

O termo $D$, é definido para duas energias distintas,descritas pelos índices $\mathrm{h}$ e $\mathrm{l}$, representando as aquisições em alta e baixa energia, respectivamente. Assim, podem ser definidas as seguintes relações: $t_{b}=f_{b}\left(D_{l}, D_{h}\right)$ e $t_{c}=f_{c}\left(D_{l}, D_{h}\right)$, onde $f_{b}$ e $f_{c}$, 
representam as funções de mapeamento das duas espessuras. A partir da obtenção das imagens em duas energias distintas, pode se construir a seguinte relação:

$$
\left(\begin{array}{c}
D_{l} \\
D_{h}
\end{array}\right)=\left(\begin{array}{cc}
\Delta \mu_{b l} & \Delta \mu_{c l} \\
\Delta \mu_{b h} & \Delta \mu_{c h}
\end{array}\right)\left(\begin{array}{l}
t_{b} \\
t_{c}
\end{array}\right)
$$

Para se criar as funções de quantificação de $t_{b}$ e $t_{c}$, seus termos devem ser isolados na equação 2.32. Ao solucionar a matriz inversa contendo os coeficientes de atenuação linear, são obtidas as seguintes equações:

$$
\begin{aligned}
t_{c} & =\frac{\Delta \mu_{b l} D_{h}-\Delta \mu_{b h} D_{l}}{\Delta \mu_{b l} \Delta \mu_{c h}-\Delta \mu_{c l} \Delta \mu_{b h}} \\
t_{b} & =\frac{\Delta \mu_{c h} D_{l}-\Delta \mu_{c h} D_{h}}{\Delta \mu_{b l} \Delta \mu_{c h}-\Delta \mu_{c l} \Delta \mu_{b h}}
\end{aligned}
$$

A partir da equação 2.33, é possível estimar a espessura da calcificação presente na mama, enquanto a equação 2.34 , pode ser utilizada para se definir uma equação que estime a fração glandular $\left(f_{g}\right)$ da mama, dada por [29]:

$$
f_{g}=\frac{t_{b} \rho_{b}}{T \rho_{a}+t_{b}\left(\rho_{b}-\rho_{a}\right)}
$$

Sendo, $\rho_{b}$ e $\rho_{a}$, as densidades dos tecidos glandular e adiposo, respectivamente. 


\section{Capítulo 3}

\section{Materiais e Métodos}

\subsection{Construção do Modelo Geométrico}

A figura 3.1 exibe o modelo geométrico padrão simulado no PENELOPE para a execução desta dissertação:

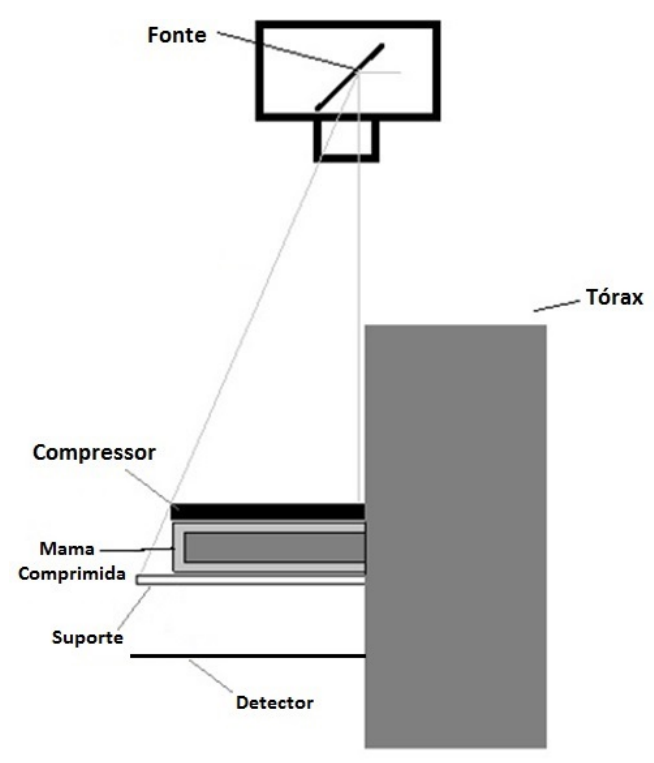

Figura 3.1: Modelo geométrico utilizado nesta dissertação.

Foi utilizada uma fonte monoenergética gerada a partir de um ponto focal com 0,3 mm à uma distância de $65 \mathrm{~cm}$ de um detector ideal contendo 201x201 pixels, sendo que cada pixel possui dimensões de $100 \mu \mathrm{m}$. O compressor foi composto de acrílico com $3 \mathrm{~mm}$ de espessura. Logo abaixo da mama, se encontra um suporte de carbono de 2,1 $\mathrm{mm}$ de espessura, a uma distância de 2,2 $\mathrm{cm}$ do detector. O tórax foi composto de água e possui dimensões de 40x15x50 cm. A modelo da mama é 


\begin{tabular}{|c|c|c|c|c|c|c|}
\hline \hline \multicolumn{7}{c}{ Composição Elementar } \\
\hline Tecido & $\mathrm{g} / \mathrm{cm}^{3}$ & $\mathrm{H}$ & $\mathrm{C}$ & $\mathrm{N}$ & $\mathrm{O}$ & $\mathrm{P}$ \\
\hline Adiposo & 0,93 & 11,2 & 61,9 & 1,7 & 25,1 & 0,1 \\
Glandular & 1,04 & 10,2 & 18,4 & 3,2 & 67,7 & 0,5 \\
\hline
\end{tabular}

Tabela 3.1: Composição elementar dos tecidos adiposo e mamário.

descrito na seção a seguir.

\subsubsection{Modelo da Mama}

A figura 3.2, ilustra o modelo da mama utilizado neste trabalho:

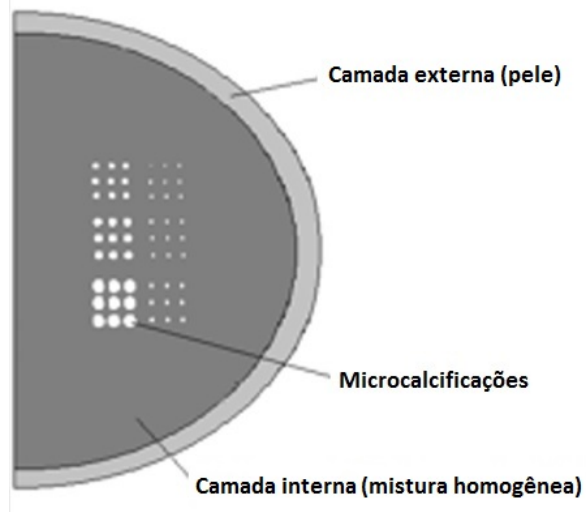

Figura 3.2: Modelo geométrico da mama.

Foram consideradas mamas semicirculares com raio de $8 \mathrm{~cm}$ e espessuras de 2, 4 e $6 \mathrm{~cm}$, com uma camada externa de pele (material disponível na base de dados do PENELOPE) de 1,45 mm de espessura, e uma camada interna, composta por uma mistura homogênea entre tecidos adiposo e glandular, em diferentes proporções (25, 50 e $75 \%$ de glandularidade). A tabela 3.1 exibe a composição elementar da camada interna da mama, proposta por Hammerstein [51] e utilizada neste trabalho para a construção do tecido mamário. Calcificações foram aplicadas na mama, sendo compostas de $\mathrm{CaCO}_{3}$ em formas esféricas com diâmetros entre 100 e $600 \mu \mathrm{m}$, organizadas em grupos de 9 componentes de mesmo tamanho. 


\subsection{Adaptação do Código e Sua Validação}

Apesar de fornecer uma grande quantidade de dados sobre o transporte e interação das partículas incidentes, o código PENELOPE não fornece todos os dados necessários para a formação de uma imagem e a quantificação da dose glandular e exposição (ou kerma). Além disso, uma partícula primária que sofre uma interação e tem sua trajetória alterada, ainda continua sendo retratada pelo código como primária, enquanto as partículas secundárias são somente aquelas geradas após uma interação, como os elétron ejetados por efeito fotoelétrico ou efeito Compton [31]. Devido a esses fatores, se viu necessária a adaptação do PENELOPE para a aquisição dos dados necessários. A validação do código adaptado foi realizada envolvendo grandezas que caracterizam a qualidade de uma imagem mamográfica e dose.

\subsubsection{Separação Entre Feixes Primário e Secundário}

O primeiro passo da adaptação do código foi realizar a discriminação entre os feixes primário e secundário. Esta etapa permitiu a geração das imagens mamográficas geradas apenas por fótons primários, além de possibilitar o cálculo do fator espalhado-primário (SPR), necessário para aplicação do algoritmo de correção de espalhamento da imagem e estudos na degradação de contraste. Para esta separação, foi aplicada uma condicional no código que considera como partículas primárias, apenas aquelas que chegassem no detector com a mesma energia, direção e ângulo de emissão da fonte. As demais partículas foram consideradas como espalhadas.

Para a validação da separação das partículas, foram feitas comparações entre resultados adquiridos de SPR neste trabalho e os adquiridos em outros trabalhos. Este parâmetro foi escolhido, pois como dito anteriormente, afeta diretamente a degradação de contraste das imagens, um fator de grande importância para a execução desta dissertação.

Chan\&Doi [71] e Boone [72] realizaram testes por simulação que determinaram a razão entre o número de fótons espalhado e primário gerados por uma fonte estreita que atravessam um fantoma infinitamente largo, chamado 
de $S P R_{\text {inf }}$. Em ambos os trabalhos, foi utilizado um feixe estreito de $60 \mathrm{keV}$ atravessando um fantoma de água de 10 ou $20 \mathrm{~cm}$ de espessura, chegando em um detector de NaI. O modelo foi reproduzido e foram obtidos valores de $S P R_{\text {inf }}$ em função da largura do feixe incidente, sendo comparados com os valores obtidos nesses artigos.

Cunha [57] avaliou a razão entre as energias totais das partículas espalhadas e das partículas primárias que chegam em um detector, determinado como $S P R_{e}$. De acordo com o artigo, o modelo geométrico possui características semelhantes ao modelo utilizado neste trabalho. A fonte utilizada pelo autor é polienergética de 28 $\mathrm{kVp}$ (Mo/Mo).A camada externa da mama é composta por material adiposo e sem a presença de calcificações. Por fim, foi utilizado um detector de $\mathrm{Gd}_{2} \mathrm{O}_{2} \mathrm{~S}$ e não há um suporte de carbono, fazendo com que o detector esteja localizado logo abaixo da mama. Este modelo geométrico foi reproduzido, a fim de se determinar os valores de $S P R_{e}$ para mamas com espessuras entre 2 e $8 \mathrm{~cm}$.

Para os testes de validação de SPR, foram feitos levantamentos comparativos através de gráficos, ilustrando a diferença entre os resultados deste trabalho e da literatura.

\subsubsection{Cálculo das Grandezas Dosimétricas}

O próximo passo na adaptação, foi gerar uma sequência de código que especifique as grandezas dosimétricas importantes para a realização dos estudos. A dose total absorvida pela mama, $D_{m}$, foi cálculada ao dividir a energia absorvida pela camada interna da mama, $E_{m}$, por sua massa, $M$, e multiplicada por um fator de conversão de unidades ( $\mathrm{de} \mathrm{eV} / \mathrm{g}$ para $\mathrm{mGy}$ ), como mostrado na equação a seguir:

$$
D_{m}=\left(\frac{E_{m}}{M}\right) \times 1,602.10^{13}
$$

Este dado é de grande importância para a construção de figuras-de-mérito (FOM), que será explicado mais à frente neste capítulo.

O primeiro passo para se obter $D_{g N}$, foi estimar a dose glandular média, $D g$, 
dada pelo:

$$
D_{g}=\left(\frac{E_{m}}{M_{g}}\right) \times 1,602.10^{13} \times G,
$$

Sendo $M_{g}$ a massa do tecido glandular que compõe a camada interna da mama, dada por:

$$
M_{g}=M \times f_{g}
$$

Onde, $f_{g}$ indica a fração glandular correspondente da mama. O fator G foi proposto por Boone [56] e é dado pela equação a seguir:

$$
G=\frac{f_{g} \cdot\left(\frac{\mu_{e n}}{\rho}\right)_{g}}{f_{g} \cdot\left(\frac{\mu_{e n}}{\rho}\right)_{g}+\left(1-f_{g}\right) \cdot\left(\frac{\mu_{e n}}{\rho}\right)_{a}}
$$

Sendo, $\left(\mu_{e n} / \rho\right)_{g}$ e $\left(\mu_{e n} / \rho\right)_{a}$, os coeficientes mássicos de absorção de energia dos tecidos glandular e adiposo, respectivamente. Estes coeficientes foram calculados através da equação 2.10. Os coeficientes mássicos de absorção dos elementos que compões os tecidos adiposo e glandular, foram retirados da base de dados do NIST [73] e suas frações de massa são mostrados na tabela 3.1.

Como citado no capítulo 2, a normalização da dose glandular média é feita através do kerma no ar, ou da exposição na entrada da pele $\left(X_{e}\right)$ e permite calcular $D g N$. Para se obter os valores de exposição, o código PENELOPE foi adaptado para calcular os valores dos coeficientes de transferência de energia " $\mu_{t r}$ "do ar $\left(\mathrm{cm}^{2} / \mathrm{g}\right)$, em função da energia dos fótons (eV).Para isso, foi ajustada uma equação exponencial baseada nos valores adquiridos por Higgins [36], como mostrado a seguir:

$$
\mu_{t r}(E)=14,96 \times 10^{\frac{-E}{4872,99}}+1,1911 \times 10^{\frac{-E}{11758,92}}+197,384 \times 10^{\frac{-E}{2213,84}}+0,0231
$$

Com os valores adquiridos, foi possível calcular o Kerma no ar na superfície da mama, utilizando a equação 2.19, e consequentemente, a exposição de entrada na pele. Através destas grandezas, pode ser calculada a $\mathrm{DgN}$, de acordo com a equação 2.25 .

A $\operatorname{DgN}$ foi escolhida para a validação do código, pois vem servindo como parâmetro de referência para cálculos de dose glandular em mamografia clínica [56], além de não depender da fluência de partículas primárias incidentes na mama. 
O primeiro teste de validação se deu pela análise da DgN para feixes monoenergéticos, em função da energia do feixe. Boone [56] utilizou um modelo geométrico envolvendo uma de mama de $2 \mathrm{~cm}$ de espessura e $8 \mathrm{~cm}$ de raio com uma camada interna de tecido adiposo e uma camada de pele de $5 \mathrm{~mm}$ de espessura. A distância entre a fonte e a base da mama não foi especificada, porém, é ilustrado que o feixe incide sobre toda a mama. Esse modelo foi reproduzido e os valores de DgN em função da energia incidente foram calculados e posteriormente comparados.

A análise com feixes polienergéticos se deu com base nos estudos de Boone [56] e Cunha [57], no qual foi feito um levantamento dos valores de DgN em função da espessura da mama nos dois casos.

Assim como para a validação de SPR, foram feitos levantamentos comparativos através de gráficos, ilustrando a diferença entre os valores de DgN adquiridos neste trabalho e na literatura.

\subsubsection{Aquisição de imagens}

A aquisição de imagens no código foi realizada a partir da implementação de mapas contadores de fótons ou energia depositada, introduzidos no volume que compreendia o detector, considerando a região que se encontravam as microcalcificações. O tamanho dos pixels é de $100 \mu \mathrm{m}$, sendo suficiente para detectar a menor calcificação simulada. Os mapas foram implementados em diferentes condições, de modo que mostrassem todos os fótons que chegavam em cada pixel, exibiam apenas fótons primários, ou que consideravam somente fótons espalhados. Isso foi realizado para estudos comparativos na implementação do algoritmo de correção de espalhamento.

Para se validar o mapa gerado, foi comparado o número de fótons primários, teórico e simulado, que deveriam chegar em cada pixel. Foi calculado o número fótons primários teóricos chegando em um ponto do detector, de acordo com a equação a seguir:

$$
N i=N_{0} \times e^{-\mu_{a r} \cdot d_{a r}} \times e^{-\mu_{P M M A} \cdot d_{P M M A}} \times e^{-\mu_{p e l e} \cdot d_{p e l e}} \times e^{-\mu_{t m} \cdot d_{t m}} \times e^{-\mu_{s c} \cdot d_{s c}}
$$


Sendo $N_{0}$ e $\mathrm{Ni}$, o número de fótons incidentes e que chegam no detector, respetivamente, e $\mu_{a r} \cdot d_{a r}, \mu_{P M M A} \cdot d_{P M M A}, \mu_{\text {pele }} \cdot d_{\text {pele }}, \mu_{t m} \cdot d_{t m}$ e $\mu_{c} \cdot d_{c}$, o produto entre os coeficientes de atenuação e as espessuras de ar, PMMA, pele, tecido mamário e suporte de carbono, respectivamente. Os valores de coeficiente de atenuação do material, foram adquiridos através da base de dados do NIST [40].

\subsection{Estudo do Contraste, Ruído e Razão Contraste-Ruído}

Nesta etapa, foi realizada a avaliação da dependência dos parâmetros que afetam a visualização das calcificações, para diferentes condições de simulação (diversas espessuras de mama, doses absorvidas, energias de feixes e espessuras de microcalcificações).

O contraste objeto, $S C$, de uma calcificação foi adquirido ao relacionar seu sinal com o do background, sendo calculado de acordo com a equação 2.14:

O ruído (N) da imagem foi dado pelo desvio padrão do sinal adquirido no background, seguindo uma distribuição de Poisson, como mostrado a seguir:

$$
N=\sigma_{\text {background }}=\sqrt{q_{1}}
$$

Desta forma, a razão contraste-ruído (que na prática indica o nível de visualização de um objeto), foi calculada de acordo com a equação 2.18 e 3.7:

Foram construídos gráficos que mostram os valores do contraste, ruído e CNR em função das diferentes condições de simulação citadas. Os comportamentos observados foram devidamente justificados através dos princípios físicos e previsões literárias.

\subsection{Processamentos e Combinação das Imagens}

O processo de combinação utilizado neste projeto, que permite as estimativas de espessuras de calcificações e frações glandulares, se utiliza de imagens que consideram apenas os sinais gerados por feixes primários [14], o que indica uma necessidade de aplicação de um algoritmo que elimine a contribuição dos fótons espalhados nas imagens adquiridas, entretanto, este procedimento propaga ruído nas 
imagens resultantes, o que prejudica a visualização das calcificações nas imagens combinadas. Desta forma, métodos de correção de ruído foram implementados e comparados, sendo escolhido, àquele que apresentou a melhor eficiência.

\subsubsection{Pré-Processamento: Correção de Espalhamento}

A implementação do algoritmo de pré-processamento seguiu as especificações descritas por Ducote\&Molloi [74] e foi aplicada em MatLab ${ }^{\circledR}$. Considerando o sinal detectado no pixel (Im), como a convolução das contribuições primária (Ip) com um kernel de espalhamento $g_{s}$, temos:

$$
I_{m}=I_{p} * g_{s}
$$

É possível isolar a componente primária,caso seja possível conhecer $g_{s}$, utilizando uma deconvolução após a aplicação de uma transformada de Fourier:

$$
\begin{array}{r}
F\left(I_{m}\right)=F\left(I_{p} * g_{s}\right) \\
F\left(I_{m}\right)=F\left(I_{p}\right) \times F\left(g_{s}\right) \\
F\left(I_{p}\right)=\frac{F\left(I_{m}\right)}{F\left(g_{s}\right)} \\
I_{p}=F^{-} 1\left(\frac{F\left(I_{m}\right)}{F\left(g_{s}\right)}\right)
\end{array}
$$

O kernel $\left(g_{s}\right)$, definido por Ducote [74], é:

$$
g_{s}=\frac{\delta(r)}{r}+\frac{S P R}{(1-S P R) 2 k r} \cdot e^{\frac{-r}{k}}
$$

Sendo $r$, um termo radial para modelos analíticos de raios $\mathrm{X}$ espalhados, proposto por Boone e Seibert [75]. O termo $\delta(r)$ é uma função delta que representa o mapeamento do componente primário e $k$, é distancia média de propagação do raio x espalhado. Os valores de $S P R$ e $k$ foram obtidos através de valores tabelados pelo autor que propõe o algoritmo apresentado acima [74].

Para se avaliar o algoritmo, foi feito o cálculo da porcentagem de erro do valor quadrático médio (RMSpe), que estima a diferença entre os valores absolutos de pixel adquiridos na imagem corrigida, com os valores adquiridos na imagem gerada apenas por feixes primários (estas imagens foram geradas apenas para este 
fim comparativo). Como análise adicional, foi feito um levantamento de RMSpe entre as imagens geradas sem correção e as imagens primárias. O cálculo de RMSpe é dado pela seguinte equação:

$$
R M S_{p e}=\frac{100}{\sqrt{n}} \sqrt{\sum_{i=1}^{n}\left(\frac{I_{p e}-I_{p a}}{I_{p a}}\right)^{2}}
$$

Onde, n é o número de pixels da imagem e $I_{p e}$ e $I_{p a}$, são os valores de pixel das imagens estimada e adquirida, respectivamente. Como esses valores também foram adquiridos pelos autores citados nesta etapa, foram feitas comparações entre os valores médios encontrados por ambos os trabalhos.

Após a aplicação da correção de espalhamento, a técnica de dupla energia segue com a combinação das imagens pré-processadas.

\subsubsection{Algoritmo de Combinação: Estimativas de Calcificações e Frações Glandulares}

A combinação das imagens de baixa e alta energias basea-se no fato apontado por Kappadath [76], que quanto maior a separação entre as energias, menor o ruído propagado na imagem resultante, portanto, o intervalo de baixa energia foi considerado como as imagens adquiridas entre 16 e $37 \mathrm{keV}$, enquanto o intervalo de alta energia, correspondia às aquisições de 38 a $80 \mathrm{keV}$.

A combinação das imagens se deu de acordo como mostrado na seção 2.4.3 e as quantificações da espessura das microcalcificações e fração glandular, se deram por 2.33 e 2.35, respectivamente. Esta etapa foi desenvolvida no MatLab ${ }^{\circledR}$.

Para cada energia, foi simulada uma imagem de referência, necessária para o cálculo de $D_{h}$ e $D_{l}$. As imagens referências foram simuladas a partir de um modelo de mama sem a presença de calcificações e com a camada interna composta apenas de tecido adiposo. Estas imagens também receberam o procedimento de correção de espalhamento.

Os valores de $\Delta \mu_{b l}, \Delta \mu_{b h}, \Delta \mu_{c l}, \Delta \mu_{c h}$, se deram de acordo a obtenção dos coeficientes de atenuação linear dos tecidos glandular e adiposo e do CaCO3, adquiridos a partir da base de dados do NIST [40]. 
Os valores das densidades, $\rho_{b}$ e $\rho_{a}$, foram propostos por Hammerstein et al. [51], sendo utilizados na quantificação da fração glandular em cada simulação, dada pela equação 2.35 .

Tanto o processo de correção de espalhamento quanto o processo de combinação, propagam ruído nas imagens quantitativas, o que prejudica consideravelmente a visualização das calcificações, sendo necessária a implementação de um algoritmo de pós-processamento (para redução de ruído) nestas imagens, como mostrado na seção a seguir.

\subsubsection{Pós-Processamento: Correção de Ruído}

Foram aplicadas três técnicas de correção de ruído neste trabalho, sendo dois tipos comuns de filtros (boxcar e mediana) e um específico, chamado de Kalender Noise Reduction (KNR). Os filtros utilizados no processamento das imagens, foram implementados no MatLab ${ }^{\circledR}$.

\subsubsection{Filtro Boxcar}

O filtro boxcar é o tipo mais simples de filtragem de sinal, que suaviza a imagem ao retornar a média dos valores de uma determinada janela,(t) de pixels em sua vizinhança [77]. A aplicação do filtro se deu do seguinte modo:

$$
\begin{gathered}
\left(t_{c}\right)_{i, j}=\left(\left(D_{l}\right)_{i, j},\left(D_{h}\right)_{i, j}\right) \\
\left(t_{c}\right)_{i, j}^{\prime}=\frac{1}{t^{2}} \sum_{k=-(t-1 / 2)} \sum_{l=-(t-1 / 2)}^{(t-1) / 2}\left(t_{c}\right)_{i+k, j+l}
\end{gathered}
$$

No cálculo, foi utilizada uma janela de 3x3 pixels para as filtragens.

\subsubsection{Filtro Mediana}

O filtro mediana funciona como o boxcar, mas ao invés de considerar a média de uma janela, o método substitui o valor do pixel pela mediana dos valores que 
correspondem à sua vizinhança. É sugerida pela literatura [17, 78], a aplicação do filtro mediana na imagem de alta energia, conforme mostrado a seguir:

$$
\begin{gathered}
\left(D_{h}^{\prime}\right)_{i, j}=\left[\text { mediana }\left(D_{h}, \text { kernel }\right)\right]_{i, j} \\
\left(t_{c}\right)_{i, j}^{\prime}=t_{c}\left(\left(D_{l}\right)_{i, j},\left(D_{h}^{\prime}\right)_{i, j}\right)
\end{gathered}
$$

De acordo com a referência [78], foi utilizado um kernel de 5 pixels para uma mama com fg maior ou igual à $50 \%$ e 3 pixels para menos que $50 \%$. Ao se filtrar a imagem de alta energia, se diminui o ruído propagado pelo processo de combinação.

\subsubsection{Filtro KNR}

Este filtro foi proposto por Kalender [79], visando reduzir ruídos ao se aproveitar da correlação entre o tecido glandular e o tecido de calcificação. Primeiramente, foi aplicada uma filtragem passa alta no mapa de fração glandular (fg), como um estimativa de correlação entre os mapas de $t_{c}$ e fg, como previsto por Ergun [70].

$$
\left(f_{g}\right)_{i, j}^{\prime}=\left(f_{g}\right)_{i, j}-\frac{1}{t^{2}} \sum_{k=-(t-1 / 2)}^{(t-1) / 2} \sum_{l=-(t-1 / 2)}^{(t-1) / 2}\left(f_{g}\right)_{i+k, j+l}
$$

Este procedimento foi implementado no Mat Lab ${ }^{\circledR}$, de forma que fosse encontrado o valor que filtrasse a imagem com maior eficiência, resultando no menor desvio padrão encontrado nas intensidades dos pixels da imagem final. Após isso, foi aplicada a seguinte relação:

$$
\left(t_{c}\right)_{i, j}^{\prime}=\left(t_{c}\right)_{i, j}+s \cdot\left(f_{g}\right)_{i, j}^{\prime}
$$

Sendo s, o fator de ponderação para minimização do ruído. Kappadath [78] estimou os possíveis valores de s otimizados para diversas características de simulação. Esses valores foram aplicados no código do $\operatorname{MatLab}^{\circledR}$ de forma recursiva, até que fosse encontrado o valor que minimizasse o ruído do background da imagem tratada.

Para estudar os efeitos de cada algoritmo, foi levantada a percentagem de ruído que cada filtro foi capaz de eliminar (através dos valores de desvio padrão das imagens geradas), além de uma análise qualitativa da visibilidade das calcificações. 


\subsection{Considerações Para Otimização}

\subsubsection{Estimativa da Fração Glandular}

A partir da equação 2.35, foi possível construir um mapa de contorno, contendo os valores de exatidão das estimativas de fração glandular, simuladas para cada combinação de baixa e alta energias. A partir deste mapa, foi possível avaliar a eficiência do algoritmo e destacar as combinações que apresentaram as melhores estimativas.

\subsubsection{Estimativa da Espessura de Microcalcificações}

Nesta etapa, foi ajustado o intervalo de energias ótimas que melhor estimaram as frações glandulares, de forma a melhor estimar também, as espessuras das calcificações presentes na mama. Tão importante quanto estimativa das dimensões de uma calcificação, é sua detectabilidade. Para isso, deve ser analisado o CNR das calcificações para cada combinação. Porém, a dose cedida na mama não foi fixada para cada aquisição, assim, não se pode considerar apenas o CNR, mas também, a dose na mama.

\subsubsection{Figuras de Mérito (FOM)}

A FOM de maneira geral, representa o desempenho de um sistema sob uma determinada condição e é geralmente utilizado como parâmetro principal na otimização de imagens mamográficas[80, 81, 82, 83]. Foi determinado na literatura $[13,15]$ que a melhor forma de definir a FOM de uma imagem combinada de dupla energia, de acordo com a seguinte equação:

$$
F O M=\frac{C N R^{2}}{D_{g l}+D_{g h}}
$$

Onde $D_{g l}$ e $D_{g h}$ são as doses glandulares absorvidas pela mama nas aquisições de baixa e alta energias, respectivamente. Para uma melhor compreensão dos valores, foi feita uma normalização da FOM, dividindo cada valor adquirido, pelo valor máximo alcançado nas combinações.

$$
F O M_{N}=\frac{F O M}{F O M(\text { maximo })}
$$


Esse parâmetro foi utilizado como ferramenta de auxílio para as escolhas de otimização, em conjunto com o teste de acurácia das estimativas.

\subsubsection{Acurácia das Estimativas}

A avaliação da acurácia das calcificações foi feita pelo levantamento da exatidão e precisão das combinações realizadas. A precisão das combinações (em $\%$ ), dada por $\sigma t_{c}$, se deu pela equação a seguir:

$$
\sigma t_{c}=100 \times\left(\frac{\sigma t_{c m}}{t_{c m}^{-}}\right)
$$

Considerando $t_{c m}^{-}$, a espessura média estimada de um determinado grupo de microcalcificações com mesmo diâmetro, e $\sigma t_{m}$, o desvio padrão destas estimativas.

A exatidão (em \%), estimada por Exat $t_{t c}$, é dada pela seguinte equação:

$$
\operatorname{Exat}_{t c}=100 \times\left(1-\left|\frac{t_{c m}-t_{c s}}{t_{c s}}\right|\right)
$$

Sendo, $t_{c s}$, a espessura real das microcalficicações. Foi calculada a média dos valores de exatidão encontrados para cada grupo de calcificações de mesmo tamanho. Os parâmetros apresentados foram utilizados para se escolher as combinações ótimas, como mostrado na seção a seguir.

\subsubsection{Escolha das Energias Ótimas}

Foram destacados aqueles intervalos de combinações que apresentaram os maiores valores de $F O M_{N}$. Como critério primário de otimização, foi realizada uma sobreposição entre o mapa de $F O M_{N}$ e o mapa de precisão, a fim de se destacar àquela região que apresente a melhor relação entre estas grandezas. Já a sobreposição entre o mapa de $F O M_{N}$ e o mapa de exatidão foi escolhido como critério secundário de otimização, sendo utilizado para se restringir a região ótima escolhida com base no critério primário.

Com base nos levantamentos de otimização realizados em cada espessura de calcificação, foi determinado que variações de $5 \%$ nos valores de $F O M_{N}$, precisão e exatidão, foram permitidos para se definir a melhor escolha dos pares de energias ótimas (baixa e alta). 
Finalmente, os resultados alcançados deste trabalho, são apresentados em uma tabela juntamente com as combinações ótimas obtidas por diversos autores, de acordo com suas metodologias de estudo. 


\section{Capítulo 4}

\section{Resultados e Discussões}

\subsection{Modificações e Validação no Código PENELOPE}

Nesta seção, são apresentados, descritos e discutidos os resultados que validam as modificações realizadas no código PENELOPE, empregado nesta dissertação. Esta validação foi dada através da comparação entre os dados simulados e aqueles encontrados na literatura.

As comparações foram divididas em três subseções: A primeira apresenta a validação a partir dos resultados adquiridos da razão espalhado-primário (SPR); a segunda subseção apresenta a validação do cálculo realizados de dose glandular normalizada (DgN) e, por fim, a terceira subseção apresenta a validação da formação das imagens adquiridas pelo código.

\subsubsection{SPR}

A figura 4.1 mostra os resultados da razão espalhado-primário para um feixe incidindo em um corpo infinitamente largo $\left(S P R_{\infty}\right)$ para fantomas de água de 10 e $20 \mathrm{~cm}$ de espessura. Os resultados foram obtidos e comparados, em função da abertura do feixe incidente. Os dados foram comparados com os adquiridos por Boone [75] e Chan\&Doi [71].

Os resultados apontaram uma diferença máxima de $5 \%$ em relação à literatura, devido principalmente, as diferenças de bases de dados utilizados pelos estudos. Ambos os autores utilizaram dados de seções de choque de raios X 


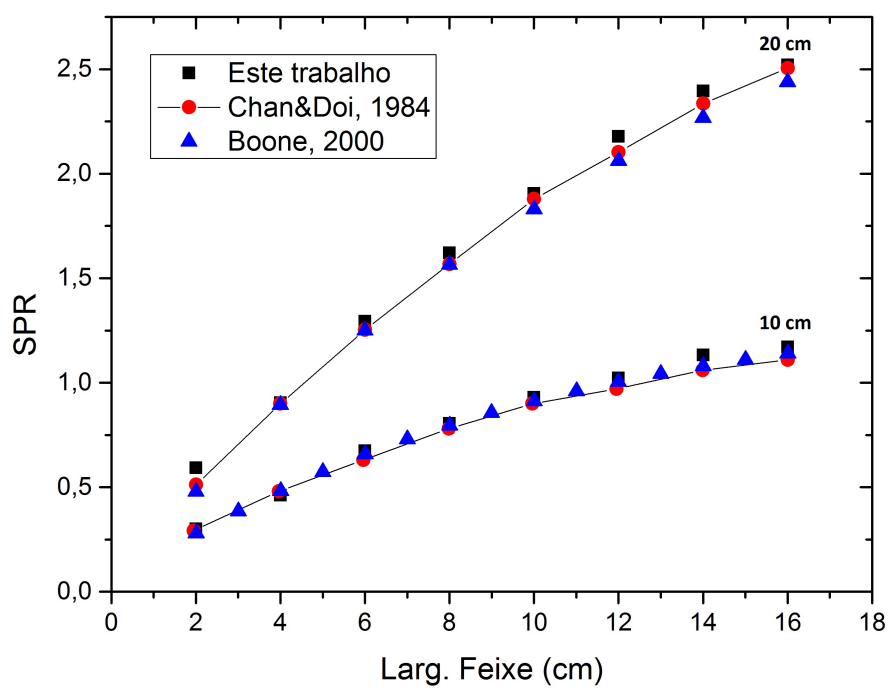

Figura 4.1: $S P R_{\infty}$ em função da largura de um feixe de $60 \mathrm{keV}$, para fantomas de 10 e $20 \mathrm{~cm}$.

adquiridos por McMaster et al. [84] e Storm \& Israel [85]. Já o código PENELOPE, utilizado neste trabalho, emprega a base de dados EPDL 97 [86].

A figura 4.2 mostra os resultados obtidos para o estudo da razão espalhado-primário, levando em consideração a energia total transmitida dos feixes primário e espalhado, $S P R_{e}$, para um feixe polienergético de $28 \mathrm{kVp}$ em função da espessura da mama e comparado com os resultados obtidos por Cunha [57].

De acordo com o gráfico, os resultados se diferenciam em no máximo 14\%, sendo que esta diferença diminui com o aumento da espessura. Isso ocorre por conta de dois fatores. O primeiro fator é a consideração da influência do efeito de interferência por espalhamentos elásticos de fótons na mama [87]. De acordo com Persliden [88], ao se considerar este efeito em determinado material, é observado um valor de seção de choque total aproximadamente $4 \%$ menor do que a encontrada em trabalhos que desconsideram este efeito [89, 90]. Isto diminui o número de fótons espalhados e aumenta o numero de fótons primários transmitidos, provocando uma diminuição no valor de SPR. O segundo fator é a diferença entre os espectros utilizados nos testes, sendo que este trabalho se utilizou de um espectro baseado nos 


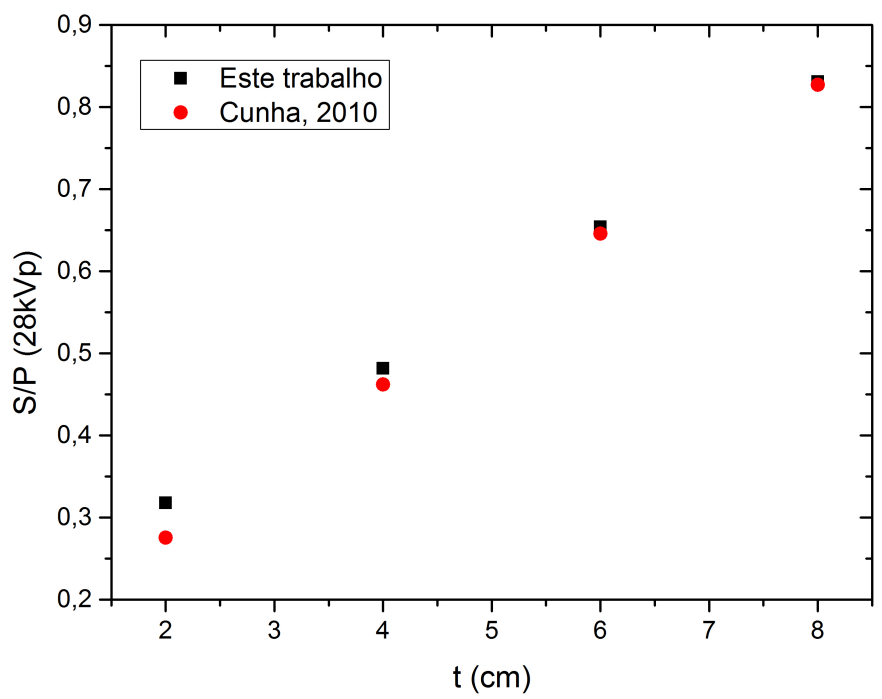

Figura 4.2: SPRe de um feixe de 28kVp (Mo/Mo) em função da espessura (t) de uma mama

cálculos de Boone [91],enquanto a referência [57] utilizou uma série de funções degrau para a aproximação do espectro. A diferença da distribuição de probabilidade para energias mais baixas causa uma flutuação maior entre os resultados obtidos entre os dois estudos para menores espessuras de mama.

\subsubsection{DgN}

A figura 4.3 mostra os valores de DgN em função da energia de um feixe monoenergético irradiando uma mama de $2 \mathrm{~cm}$.

A figura mostra uma boa concordância entre os resultados adquiridos e os da referência. A diferença entre os resultados apresentou um valor médio de $1 \%$. Esta aproximação se dá devido a utilização da mesma base de dados por ambos os trabalhos. 


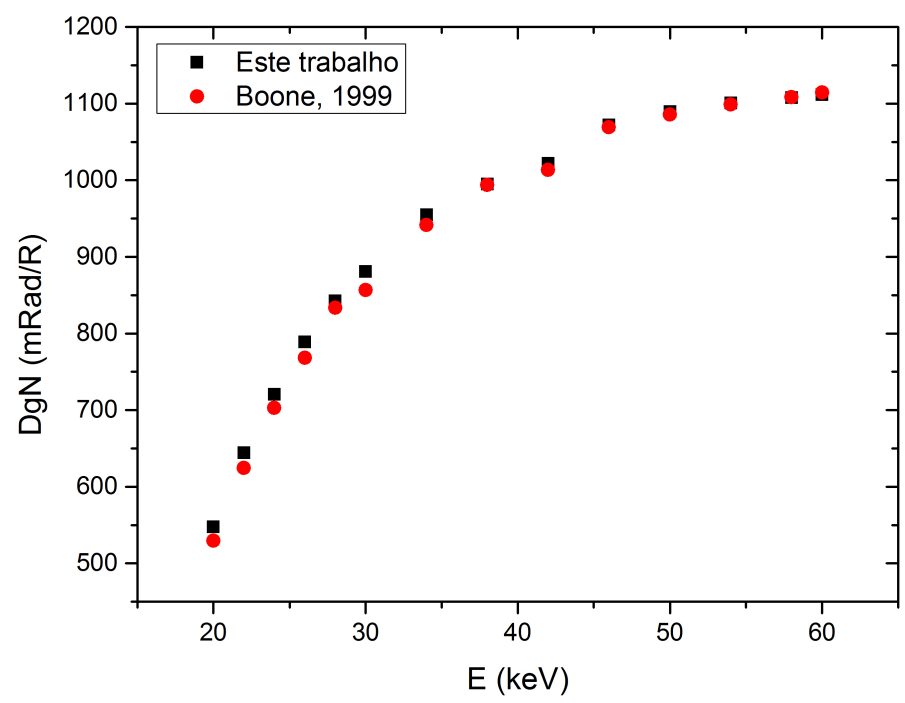

Figura 4.3: DgN em função da energia do feixe monoenergético. Comparação dos valores obtidos com os resultados de Boone, 1999.

Os resultados de DgN em função da espessura da mama, utilizando um feixe polienergético de $28 \mathrm{kVp}(\mathrm{Mo} / \mathrm{Mo})$, são mostrados na figura 4.4, juntamente aos resultados obtidos por Cunha [57] e Boone [56].

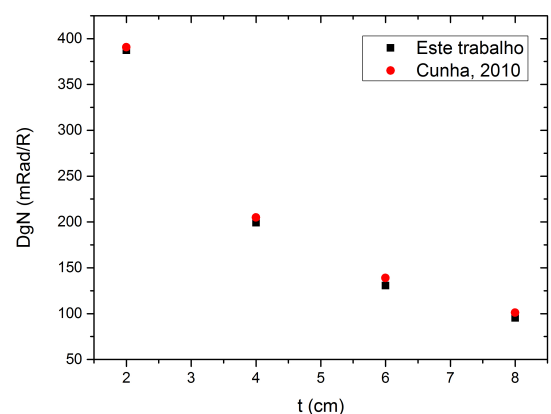

(a)

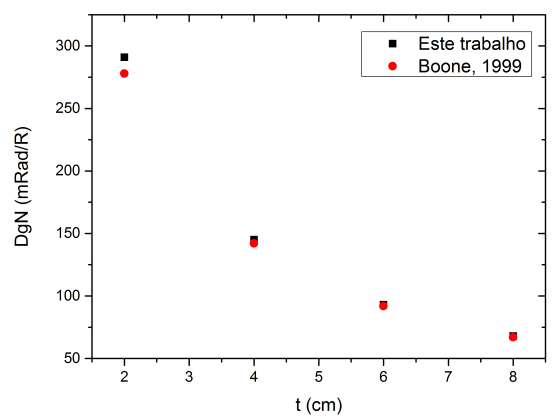

(b)

Figura 4.4: $D g N$ em função da espessura da mama (t) para os casos de fg de $50 \%$ (a) e $100 \%$ (b).

A figura mostra uma boa aproximação entre os resultados obtidos e as referências, estando abaixo dos $2 \%$ em ambos os casos. Vale ressaltar que espectro 
usado por Cunha foi obtido como explicado na etapa de análise de SPR da figura 4.2. Boone se utilizou da mesma metodologia empregada por este trabalho para a construção de seu espectro [91], porém, considerou uma resolução de energia diferente da considerada aqui, ao utilizar passos de $1 \mathrm{keV}$, enquanto neste trabalho, foi utilizado passos de $0,5 \mathrm{keV}$. Isto mostra que esta grandeza é menos sensível à resolução energética do espectro.

\subsubsection{Validação das Imagens}

A figura 4.5 mostra o número médio de fótons que chegam em cada pixel da imagem simulada, em comparação com o estimado teoricamente, por meio da equação 3.6. A análise foi feita para a mama de $4 \mathrm{~cm}$ de espessura, $50 \%$ de fração glandular e uma quantidade fixa de $4.10^{9}$ fótons.

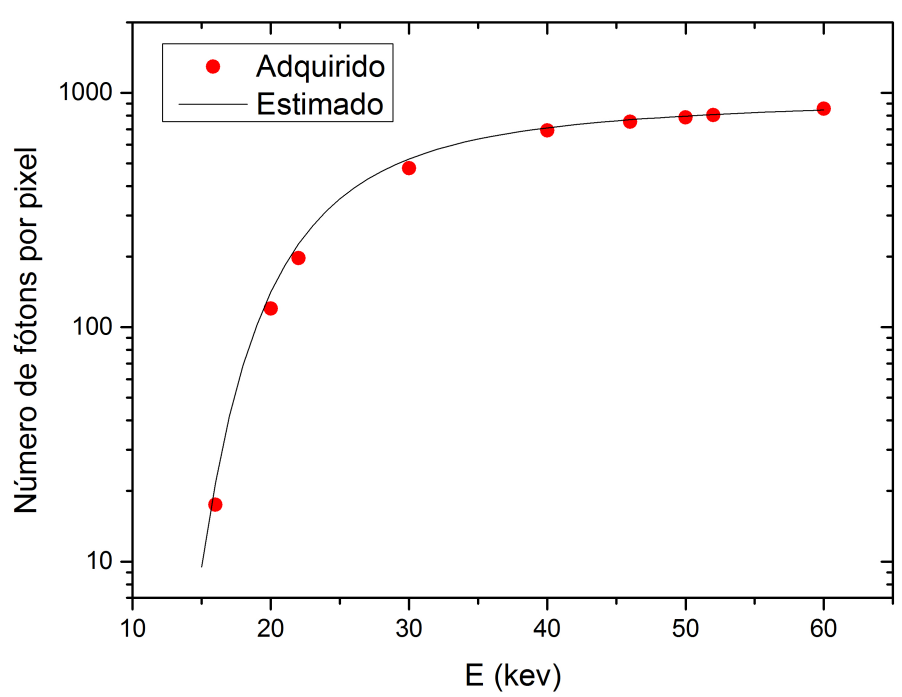

Figura 4.5: Número de fótons incidentes no detector. Valores estimados (linha) e adquiridos (pontos).

De acordo com o gráfico, os valores simulados estão coerentes com o previsto pela equação 3.6. A diferença média de $4 \%$ entre os resultados se dá pelo fato de que os valores de coeficientes de atenuação utilizados nos cálculos das estimativas foram retirados do NIST [73], sendo esta, uma base de dados diferente da utilizada 

pelo código PENELOPE.

De acordo com Poon [92], é encontrada uma diferença de até 5\% nos valores produzidos por simulações que possuam diferentes bases de dados e uma diferença de até $15 \%$ entre modelos que possuem modelos físicos distintos e utilizem a energia dos fótons menor que $1 \mathrm{MeV}$. No geral, pode-se dizer que as modificações do código estão validadas, já que todos os desvios entre os resultados estão de acordo com o previsto pela literatura.

\subsection{Simulação de Imagens e Estudos de Contraste, Ruído e Razão Contraste-Ruído (CNR)}

Os dados a seguir retratam como as características da mama (espessura e fração glandular) ou as variações nas condições de irradiação (energia do feixe e dose total na mama) influenciam na qualidade da imagem.

A figura 4.6 mostra como a espessura da mama (d) afeta o contraste, o ruído e o CNR de imagens de calcificações com $600 \mu \mathrm{m}$ de espessura. Considerando uma mama com glandularidade de $50 \%$ e feixes de $4.10^{9}$ fótons com energias de 20 e 60 $\mathrm{keV}$, para a aquisição das imagens.

É possível notar o decréscimo do contraste com a espessura na figura 4.6(a). Isto se deu pelo aumento do numero de fótons espalhados com o aumento da espessura da mama, o que elevou o SPR (como mostrado na seção 4.1.1) e consequentemente, degradou o contraste da imagem [93, 94]. Para altas energias, também foi observado um decréscimo no contraste das calcificações. Isso ocorre devido à diminuição da diferença entre os coeficiente de atenuação entre a calcificação e o tecido mamário, com a energia.

Na figura 4.6(b), nota-se que o ruído da imagem aumentou com o aumento da espessura da mama por conta da diminuição de fótons que chegam no detector. Como o coeficiente de atenuação da mama diminuiu com o aumento da energia, mais fótons são transmitidos pela mama para o feixe de $60 \mathrm{keV}$, em relação ao de $20 \mathrm{keV}$.

Os valores de CNR são mostrados na figura 4.6(c) e como pode ser observado, 


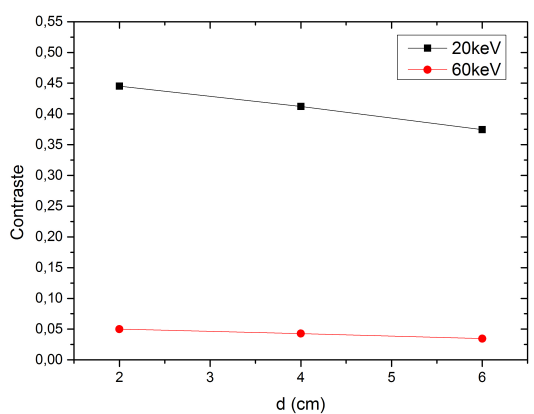

(a)

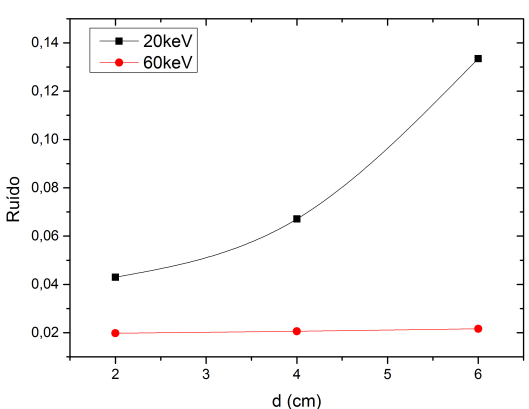

(b)

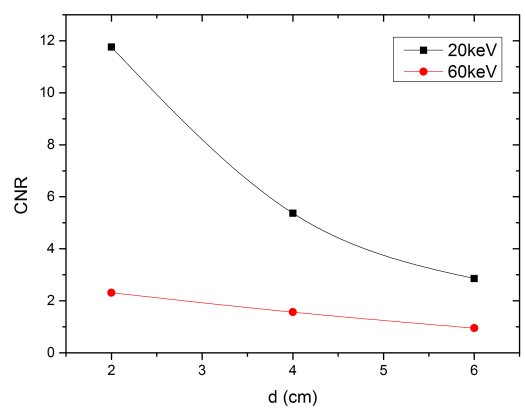

(c)

Figura 4.6: Estudo da influência da espessura da mama no contraste (a), ruído (b) e CNR (c) das imagens.

a visibilidade das calcificações diminui com o aumento da espessura da mama, influenciada tanto pela queda do contraste como pelo acréscimo do ruído. Este comportamento é previsto e observado na literatura [50, 95], para sistemas de diagnóstico por raios $\mathrm{X}$.

Para se contornar o problema do aumento de ruído para maiores espessuras de mama, é necessário aumentar o número de fótons que chegam no detector. De acordo com a literatura, sabe-se que o visibilidade das calcificações está relacionada com a dose recebida pela mama [96].

A figura 4.7 mostra a dependência do contraste e do ruído com a dose total absorvida pela mama. Foi utilizada uma mama com $50 \%$ de glandularidade e $2 \mathrm{~cm}$ de espessura e diferentes tamanhos de calcificações. 


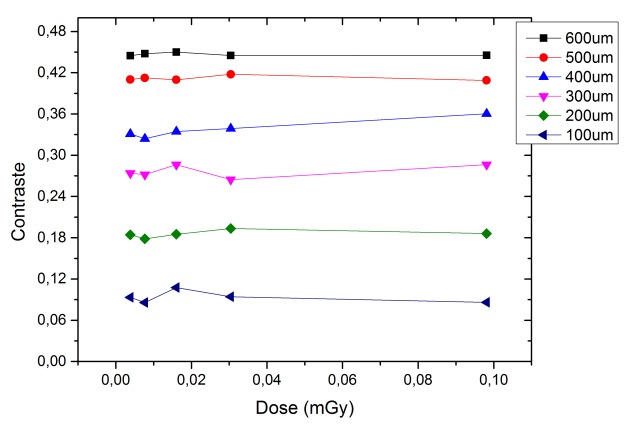

(a)

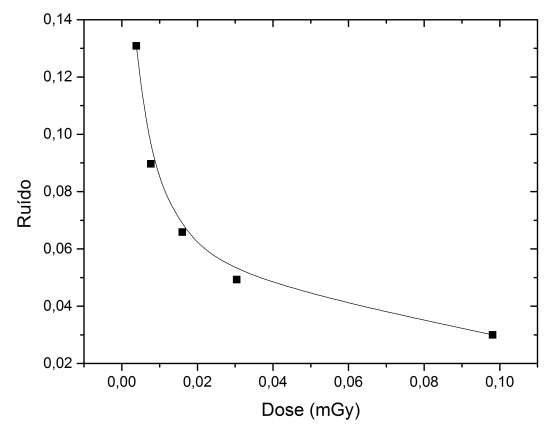

(b)

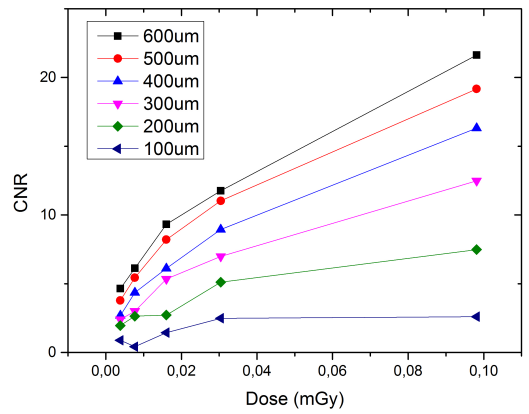

(c)

Figura 4.7: Estudo da influência da dose total absorvida no contraste (a), ruído (b) e CNR (c) das imagens.

Nota-se pela figura 4.7(a), que o contraste das calcificações pouco se alterou com o aumento da dose absorvida. Isso ocorre, pois o contraste não depende da fluência dos fótons incidentes, mas sim, da diferença entre os coeficientes de atenuação do objeto e meio, e da espessura do objeto contrastante [97], o que explica o decréscimo do contraste com a diminuição da espessura da calcificação.

Ao observar a figura 4.7(b), é visto que o ruído diminui com o aumento da dose cedida. Isso ocorre graças ao acréscimo de fótons que chegam no detector, devido ao aumento do número de fótons incidentes na mama. Com isso, nota-se um aumento da CNR das calcificações com o aumento da dose total, de acordo com a figura 4.7(c). Como o valor de CNR é diretamente proporcional à visibilidade do objeto, se pode concluir que o aumento da dose pode proporcionar uma melhora na detectabilidade das calcificações, devido a redução do ruído presente nas imagens adquiridas. 
Este comportamento foi analisado recentemente por Koukou [27], onde foi observado que o CNR possui uma relação linear com a raiz quadrada da dose.

Para uma análise qualitativa, a figura 4.8 mostra imagens adquiridas na simulação e ilustram algumas das dependências da detectabilidade dos objetos de interesse (neste caso, as microcalcificações).

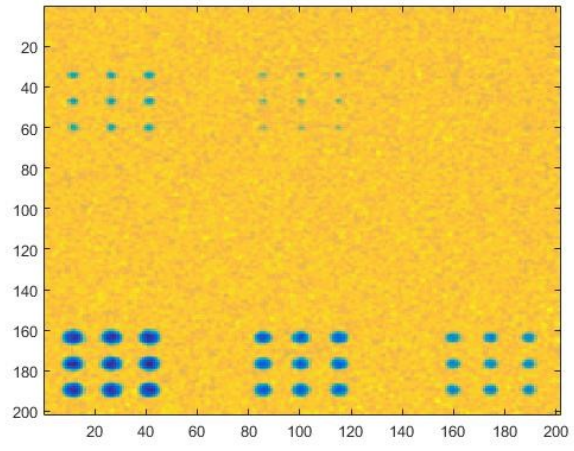

(a)

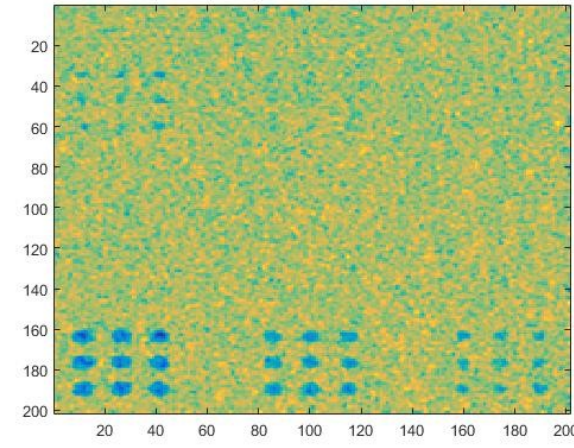

(b)

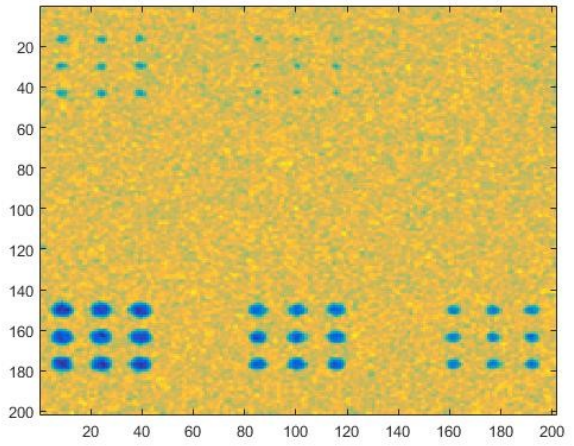

(c)

Figura 4.8: Imagens adquiridas com número fixo de $4.10^{9}$ fótons e fg de $50 \%$. Considerações para uma mama de $2 \mathrm{~cm}$ irradiadas por um feixe de $20 \mathrm{keV}$ (a) e $50 \mathrm{keV}$ (b) e uma mama de $4 \mathrm{~cm}$ irradiada por um feixe de $20 \mathrm{keV}(\mathrm{c})$.

De acordo com a figura, a visibilidade das calcificações diminuiu com o aumento da energia do feixe e da espessura da mama. O aumento da energia proporcionou uma redução de CNR predominantemente pela redução do contraste, já o aumento da espessura prejudicou a visualização das calcificações, graças ao 
aumento do ruído da imagem. Isto é visto na figura 4.8(c), como uma maior granularidade do background em relação à figura 4.8(a).

Como é percebido, em nenhuma imagem é possível distinguir as calcificações de $100 \mu \mathrm{m}$. Isso ocorre, pois para todas as condições de simulação analisadas, estas calcificações obtiveram um CNR abaixo do limiar visível.

Foi visto através das análises qualitativas e quantitativas das imagens, que o CNR mínimo em que foi possível a visualização de calcificações se encontra entre 2,5 e 3. Em 1948, Rose [98] determinou que para uma mínima visibilidade de um objeto em uma imagem, seu SNR deveria ficar entre os valores de 3 a 5 . Estudos posteriores $[99,100]$ ampliaram os resultados de Rose e concluíram que seria possível detectar em uma imagem, um objeto com SNR ou CNR no intervalo entre 2 e 5 . Assim, o limiar encontrado para este trabalho esta de acordo com previsto pela literatura.

De acordo com as figuras 4.6 e 4.7, para um melhor contraste das calcificações, deve-se irradiar a mama com um feixe de baixa energia. Já a dose deve ser tão baixa quanto razoavelmente exequível (princípio ALARA [101]), no entanto, deve-se minimizar o máximo possível o ruído. Assim, se vê necessária, a ponderação entre o ganho de CNR de uma imagem e o acréscimo da dose absorvida pela mama - Diversos autores $[17,69,15,27]$ fixam a dose total recebida, para garantir a visibilidade de microcalcificações com espessura de pelo menos $250 \mu \mathrm{m}$. Como neste projeto a dose não é fixa, foi necessária para a otimização das imagens, a consideração da relação entre a CNR e a dose absorvida (figura de mérito), que será tratada na após a análise a seguir.

Como já explicado anteriormente, o tecido mamário pode ser considerado como sendo uma mistura de tecidos adiposo e glandular. A variação da fração glandular influencia tanto a dose absorvida pela mama, quanto a qualidade de imagem, devido a alteração do coeficiente de atenuação com o conteúdo glandular [102]. Considerando a relação entre a CNR da imagem e a dose, a métrica escolhida para otimização foi a figura de mérito (FOM), sendo esta grandeza, a razão entre o quadrado da CNR e a dose glandular média. Esta relação é considerada pela literatura como a mais adequada para otimização de sistemas mamográficos digitais $[82,83]$, pois indica a habilidade do sistema de adquirir imagens com a melhor 
qualidade, combinada à menor dose glandular possível. Como citado na seção 2.3.4, a dose glandular média é a grandeza mais adequada para descrever o risco de carcinogênese associado ao exame mamográfico.

\subsection{Correção de Espalhamento}

A seguir, são mostrados os resultados da aplicação do algoritmo de correção de espalhamento proposto por Dutote\&Molloi[74], nas imagens simuladas.

A tabela 4.1 mostra os valores de RMSpe de aquisições em diferentes energias, entre as imagens geradas apenas por fótons primários e imagens com e sem correção de espalhamento. São apresentados os dados adquiridos para uma mama com $50 \%$ de glandularidade e $2 \mathrm{~cm}$ de espessura, irradiada por um feixe de $4.10^{9}$ fótons.

\begin{tabular}{|c|c|c|}
\hline \multicolumn{3}{|c}{ RMSpe } \\
\hline $\mathrm{E}(\mathrm{keV})$ & Sem Correção (\%) & Com Correção (\%) \\
\hline 20 & 41 & 3,52 \\
25 & 37 & 2,17 \\
30 & 34 & 1,50 \\
40 & 110 & 2,57 \\
50 & 89 & 2,70 \\
60 & 72 & 2,47 \\
Média & 64 & 2,49 \\
\hline
\end{tabular}

Tabela 4.1: Valores de RMSpe entre a imagens ideais e imagens sem e com correção de espalhamento.

Analisando os resultados, fica claro que o algoritmo foi eficaz em corrigir o espalhamento das imagens. A tabela mostra não só como o método é eficiente, mas também o valida de acordo com os dados produzidos no trabalho em que este algoritmo foi proposto [74]. Nele, o autor atinge um valor médio de RMSpe de 2,66\% 
para seus testes, sendo este, um valor bem próximo do valor médio adquirido por este trabalho. Em média, o algoritmo corrigiu 96\% do espalhamento das imagens.

A figura 4.9 apresenta imagens corrigidas e ideais, para uma análise visual dos resultados. São apresentadas, aquisições para energias de 20 e $40 \mathrm{keV}$.

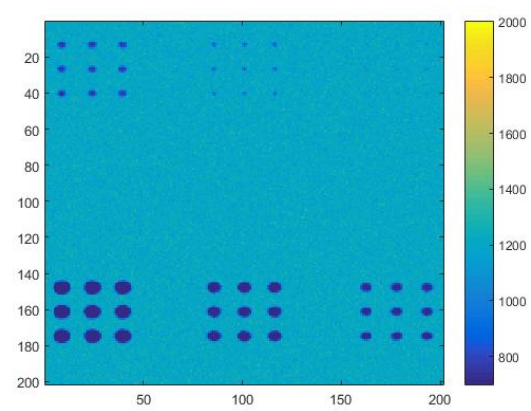

(a)

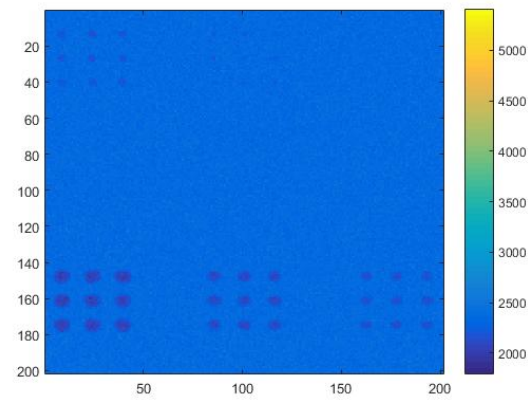

(c)

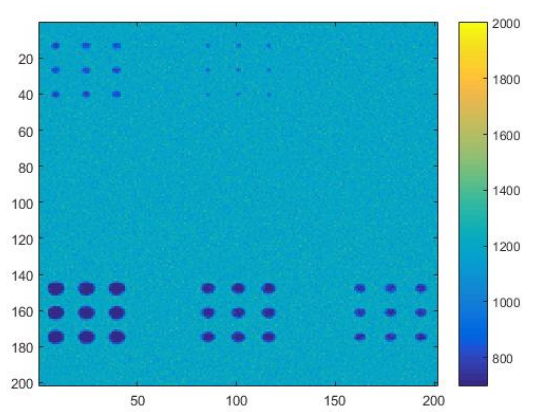

(b)

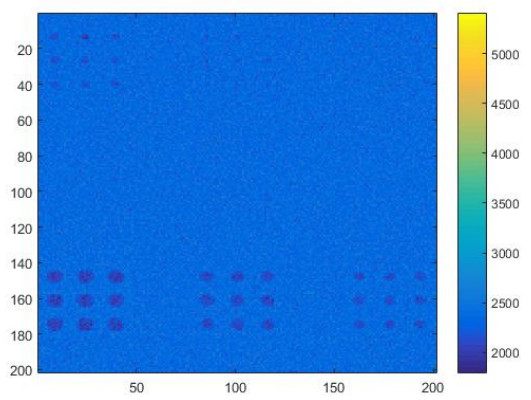

(d)

Figura 4.9: Imagens geradas a $20 \mathrm{keV}$ ideal (a) e corrigida (b) e $40 \mathrm{keV}$ ideal (c) e corrigida (d)

De acordo com a figura 4.9, há uma grande semelhança entre as imagens corrigidas e suas equivalentes ideais. Assim, se pode dizer que algoritmo conseguiu de maneira eficaz corrigir a contribuição dos feixes espalhados nas aquisições, o que validou o uso das imagens corrigidas para a seguinte etapa.

\subsection{Correção de Ruído e Combinação das Imagens}

Os resultados visuais das aplicações dos filtros boxcar e mediana são apresentados na figura 4.10. Os algoritmos foram aplicados em uma imagem gerada 
para a combinação das energias de 16 e $60 \mathrm{keV}$, adquiridas em uma mama de $2 \mathrm{~cm}$ e $50 \%$ de glandularidade, irradiada por um feixe de $4.10^{9}$ fótons.

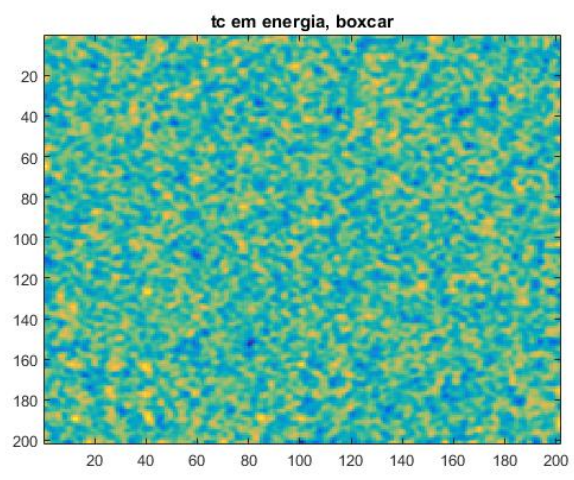

(a)

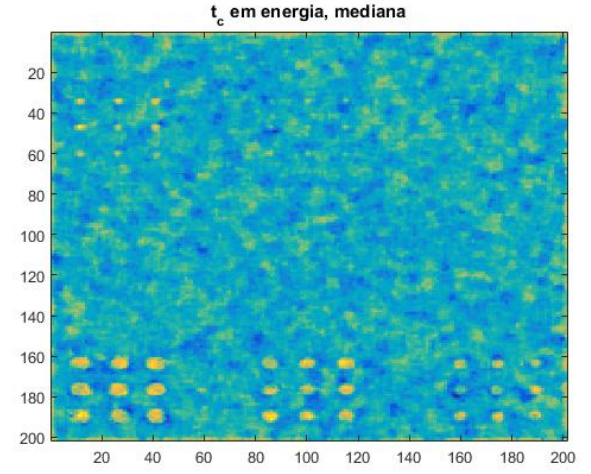

(b)

Figura 4.10: Imagens tratadas com filtro boxcar (a) e filtro mediana (b)

O filtro boxcar, permitiu uma redução de ruído das imagens em uma média de $45 \%$. Porém, sua aplicação não favoreceu a visibilidade das calcificações, pois este filtro também atua em seus sinais e em conseguinte, diminui seu contraste em relação ao background, como mostrado na figura 4.10(a).

A figura 4.10(b) mostra a utilização do filtro mediana na imagem de alta energia, o qual reduziu em média $58 \%$ o ruído das imagens combinadas e aumentou consideravelmente a visibilidade das calcificações de até $200 \mu \mathrm{m}$. O acréscimo do contraste das calcificações se deu pelo fato deste filtro manter os sinais encontrados com maior frequência em determinada janela na imagem, enquanto suaviza os demais, ao contrário do boxcar, que gera uma média entre os valores de pixel em uma região da imagem. Apesar desta melhora na visibilidade dos objetos, o ruído da imagem ainda se manteve elevado, o que prejudicou os CNRs das calcificações.

Com essa análise, pode se dizer que os dois métodos apresentados não favorecem de forma satisfatória, os estudos seguintes das imagens. A seguir, é mostrada na figura 4.11, a aplicação do filtro KNR no processamento da imagem.

$\mathrm{Na}$ imagem, é possível visualizar calcificações com diâmetros entre $600 \mu \mathrm{m}$ e $200 \mu \mathrm{m}$ de forma clara, além de um background mais homogêneo em relação à figura 4.10. O filtro KNR reduziu em média, 90\% do ruído das imagens e aumentou significativamente o contraste das calcificações. Isso porque além de se 


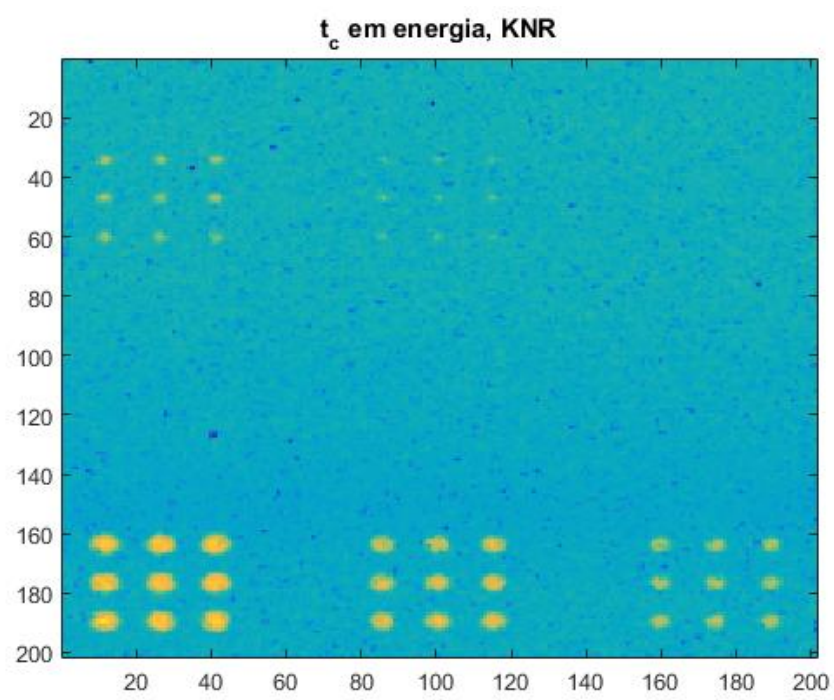

Figura 4.11: Combinação entre 16 e $60 \mathrm{keV}$ tratada com o filtro KNR.

comportar como o filtro mediana no espaço de frequência (mantém os sinais de maior intensidade), ele se aproveita da (anti-) correlação entre os ruídos proeminentes de tecido glandular e calcificações na imagem, como descrito por Kalender et al. [79] e mostrado no capítulo 3. Este filtro foi utilizado no processamento de todas as combinações, pois se mostrou o mais eficiente, justamente por explorar as características dos componentes da imagem.

Os resultados adquiridos estão de acordo com os obtidos por Kappadath et al.[78] na utilização dos mesmos filtros. Em seu trabalho, o autor obteve reduções de 20 a $45 \%$ no ruído para a aplicação do filtro boxcar, 65 a $80 \%$ na aplicação do filtro mediana na imagem de alta energia e 90 a $95 \%$ na aplicação do filtro KNR.

Para se testar a influência da técnica de correção de ruído nos resultados finais, foram feitos levantamentos de dados através de imagens processadas com o filtro mediana. As análises posteriores de escolhas das energias ótimas, não mostraram diferenças entre a aplicação do filtro mediana e o KNR, pois as mesmas combinações ótimas de energias foram encontradas. Assim, pode ser concluído que ambas as correções de ruído poderiam ser utilizadas, mas foi decidido, como mencionado anteriormente, a adoção do procedimento de correção pelo filtro KNR, por apresentar maior eficiência na correção das imagens. 


\subsection{Otimização das Imagens}

\subsubsection{Estimativa de Fração Glandular}

A figura 4.12 mostra a relação entre a exatidão das estimativas para a fração glandular em função da escolha das energias combinadas para uma mama com $50 \%$ de glandularidade e $4 \mathrm{~cm}$ de espessura.

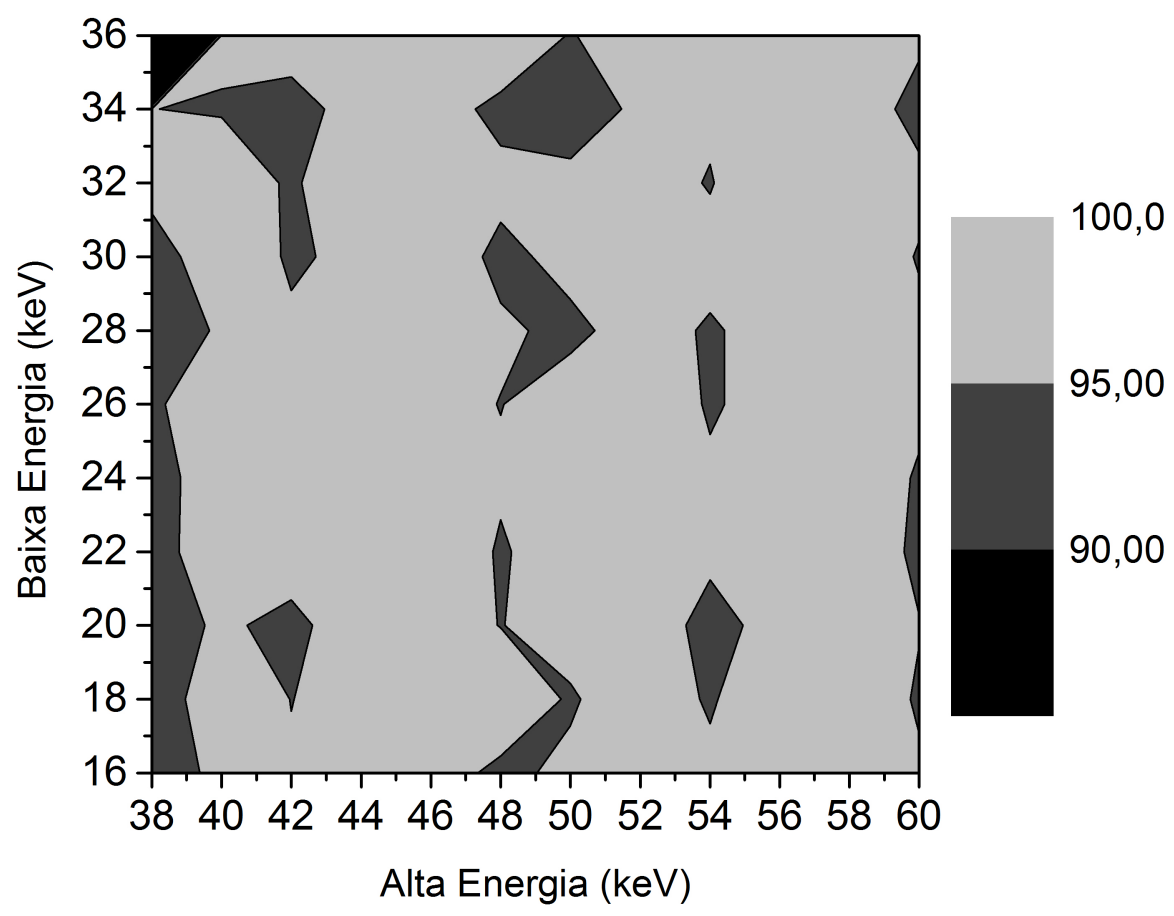

Figura 4.12: Mapa de exatidão para a estimativa da fração glandular de uma mama de $4 \mathrm{~cm}$, na combinação de diferentes energias.

De acordo com a figura, diversas combinações apresentaram uma precisão acima de $95 \%$. Isso mostra que o método utilizado para se determinar a fração glandular é eficiente para uma grande gama de combinações, sendo otimizado para diversas escolhas de energias.

Desta forma, a escolha otimizada será definida pela estimativa da espessura das microcalcificações. 


\subsubsection{Estimativa das Espessuras de Microcalcificações}

A figura 4.13 mostra mapas de FOM (normalizados) para diversas condições. Os mapas foram feitos para mamas com glandularidade de $50 \%$ irradiadas por um feixe de $4.10^{9}$ fótons. Para simplificar a visualização dos resultados, os gráficos expressam os valores encontrados de FOM até atingirem o seu pico.

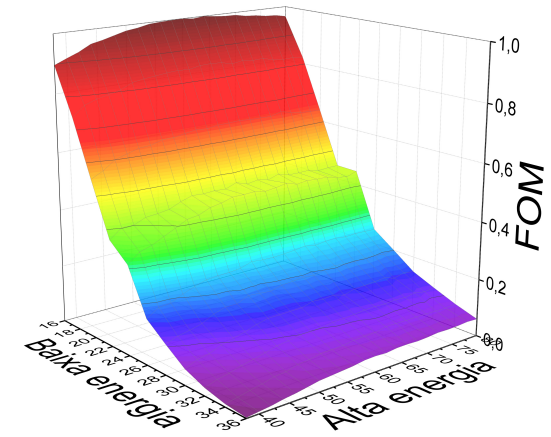

(a) $\mathrm{d}=2 \mathrm{~cm} ; \mathrm{tc}=600 \mu \mathrm{m}$

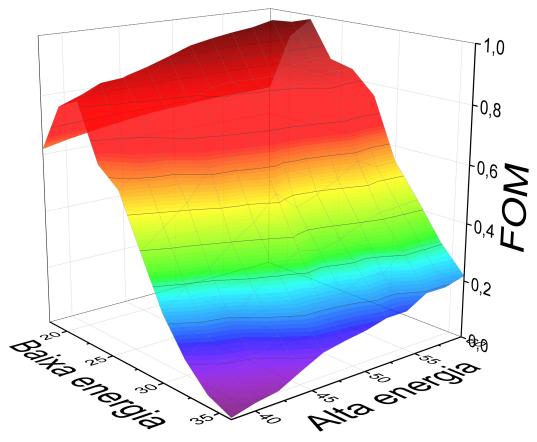

(c) $\mathrm{d}=6 \mathrm{~cm} ; \mathrm{tc}=600 \mu \mathrm{m}$

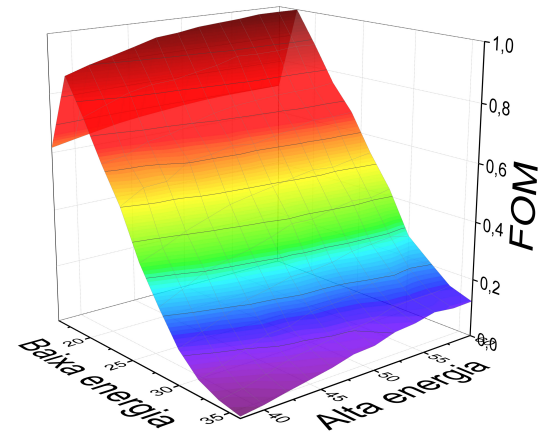

(b) $\mathrm{d}=4 \mathrm{~cm} ; \mathrm{tc}=600 \mu \mathrm{m}$

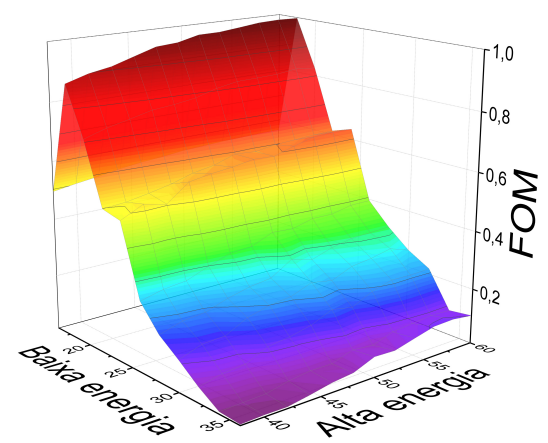

(d) $\mathrm{d}=4 \mathrm{~cm} ; \mathrm{tc}=300 \mu \mathrm{m}$

Figura 4.13: Mapas de FOM de calcificações de 600 um para mamas de $2 \mathrm{~cm}(a)$, $4 \mathrm{~cm}(\mathrm{~b})$ e $6 \mathrm{~cm}(\mathrm{c})$ e calcificações de $300 \mu \mathrm{m}$ para uma mama de $4 \mathrm{~cm}(d)$.

De acordo com a figura 4.13, o comportamento da FOM variou com a espessura da mama. A figura 4.13(a) mostra um pico de FOM em 16;64 keV. A figura 4.13(b) e 4.13(d) mostram o pico em 18;58 keV e a figura 4.13(c), indica um pico em 22;56 keV.

A partir dos estudos realizados, é visto que a componente de baixa energia pode ser responsável pela visibilidade das calcificações. Como visto na seção 4.2, o aumento da espessura da mama faz com que a visibilidade das calcificações seja 
prejudicada. Então, para se aumentar o CNR do objeto contrastante, a componente de baixa energia deve fornecer mais dose à mama, prejudicando diretamente a FOM da imagem combinada, o que explica o deslocamentos dos picos vistos na figura 4.13.

Já a componente de alta energia é vista como a responsável pela subtração do background da imagem combinada. É observado que os picos encontrados não são bem definidos para a escolha de alta energia, mostrando que esta escolha depende menos da espessura da mama. Brettle et al. [13] mostrou que a escolha de alta energia depende principalmente do tipo de receptor da imagem. Em seu artigo, o autor comparou mapas de FOM para uma determinada mama, utilizando um receptor ideal de imagem, e outro real. Em seus resultados, foi constatado que para ambos os detecores, foi obtido um pico de FOM para a mesma escolha de baixa energia $(18 \mathrm{keV})$. Porém, essa região se mostrou mais ampla para a contribuição de alta energia com o uso do detector ideal, em relação à utilização do detector real.

As figuras 4.13(b) e 4.13(d) mostram que o diâmetro da calcificação não influenciou significativamente o comportamento do FOM, uma vez que ambas apresentaram a mesma região de otimização. Para as demais espessuras de calcificações presentes nesta mama, foram obtidos sempre o mesmo comportamento de FOM.

Com base nos dados apresentados, foi feito um levantamento das combinações de energias ótimas para cada espessura de mama. Porém, como este projeto objetiva a otimização da estimativa da espessura de microcalcificações, foram levados em conta também, os mapas de precisão e exatidão das estimativas para cada combinação realizada.

A figura 4.14 mostra os mapas de acurácia da estimativa do tamanho de um grupo de microcalcificações com $400 \mu \mathrm{m}$ de espessura, além de mostrar seu mapa de FOM. Os dados foram coletados para uma mama de $4 \mathrm{~cm}$ e fração glandular de $50 \%$.

A figura 4.14 mostra com clareza, as regiões que apresentam os maiores valores de FOM, precisão e exatidão, para as combinações de energias. Com base na correlação entre os dados apresentados pelos mapas da figura 4.14, e seguindo os critérios de otimização descritos na seção 3.5.3, é definido através do critério 


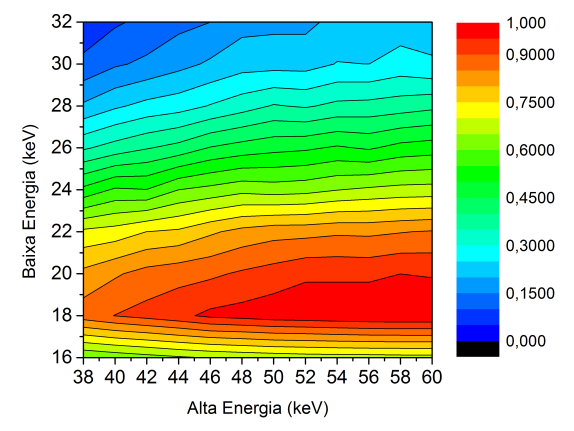

(a) Precisão

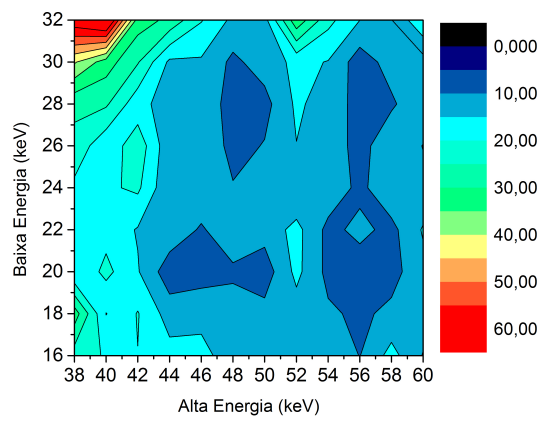

(b) Exatidão

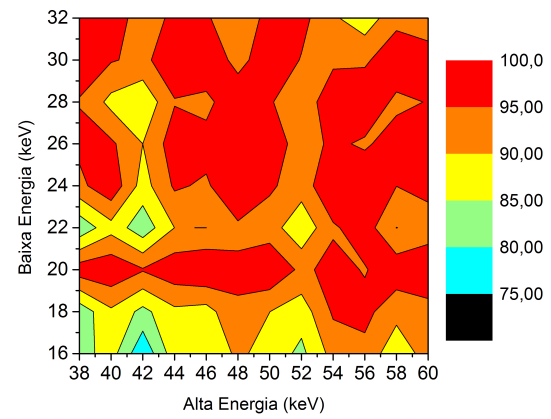

(c) FOM

Figura 4.14: Mapas de FOM e acurácia da estimativa do diâmetro de calcificações em uma mama de $4 \mathrm{~cm}$ de espessura, para diferentes combinações de energias.

primário de otimização, que a combinação de energias ótimas são de 19 keV e 56 keV. O critério secundário, mostra uma combinação ótima para as mesmas energias, o que confirma esta escolha.

Esta mesma análise foi realizada para as demais espessuras de mama, seguindo os critérios adotados, e seus resultados são mostrados na seção a seguir.

\subsubsection{Escolha das Energias Ótimas}

A tabela 4.2 mostra as combinações ótimas obtidas neste trabalho, em comparação com os resultados obtidos na literatura [17, 103, 13, 15, 27].

De acordo com a tabela 4.2, nota-se um "estreitamento"nas escolhas ótimas com o aumento da espessura da mama, porém, a escolha de baixa energia se mostra 


\begin{tabular}{|c|c|c|c|c|c|}
\hline \hline \multicolumn{5}{|c|}{ Otimizações } \\
\hline Autores & $\mathrm{d}(\mathrm{cm})$ & Fração glandular (\%) & Método de estudo & Detector & Combinações de energias \\
\hline \multirow{2}{*}{ Este Trabalho } & 2 & $25-75$ & Simulação & Ideal & $16 \pm 1 ; 62 \pm 2 \mathrm{keV}$ \\
& 4 & $25-75$ & Simulação & Ideal & $19 \pm 1 ; 56 \pm 2 \mathrm{keV}$ \\
& 6 & $25-75$ & Simulação & Ideal & $22 \pm 1 ; 56 \pm 2 \mathrm{keV}$ \\
\hline Johns \& Yaffe,1985 & 4,2 & 50 & Teórico & Ideal & $19 ; 68 \mathrm{keV}$ \\
Boone, 1991 & 4,2 & 50 & Experimental & Ideal & $19 ; 74 \mathrm{keV}$ \\
Brettle \& Cowen, 1994 & 4,1 & 50 & Experimental & Ideal e BaFBr & $18 ; 47 \mathrm{keV}$ \\
Bliznakova, et al. 2006 & 4,5 & $50-75$ & Simulação & CsI, BaFBr, $\mathrm{Gd}_{2} \mathrm{O}_{2} \mathrm{~S}$ & $21 ; 52 \mathrm{keV}$ \\
Koukou, et al. 2015 & 5 & 50 & Simulação & $\mathrm{Gd}_{2} \mathrm{O}_{2} \mathrm{~S}$ & $23 ; 58 \mathrm{keV}$ \\
\hline
\end{tabular}

Tabela 4.2: Resultados de otimização (combinação de baixa e alta energias) obtidos neste trabalho e por outros autores.

mais sensível à esta mudança. Nota-se que a escolha de baixa energia seguiu um acréscimo de 1,5 keV por centímetro de espessura mamária, já a escolha de alta energia apresentou uma redução de $3 \mathrm{keV}$ para a variação da espessura mamária de 2 para $4 \mathrm{~cm}$, se mantendo estável para o seguinte acréscimo de espessura.

Como citado na na seção 4.5.2, o aumento da espessura da mama faz com que o FOM das imagens combinadas, apresentem um pico em maiores escolhas de baixa energia, o que influenciou diretamente na escolha das energias ótimas. Porém, a escolha de alta energia foi pouco influenciada pela espessura da mama, uma vez que todas as escolhas ótimas de alta energia, mostradas na tabela, apresentaram valores sobrepostos em seus intervalos de aceitação.

Comparando os resultados da tabela, nota-se que as escolhas de baixa energia se mostraram coerentes com as obtidas pelos autores que se utilizaram de detectores ideais, porém, a escolha de alta energia não foi bem definida entre os autores. Já aqueles que se utilizaram de detectores reais, obtiveram um desvio na escolha de baixa energia em espessuras de mama semelhantes, indicando que o detector pode exercer influência sob as escolhas.

Cabe salientar que uma diferença entre os trabalhos citados e este, é a escolha da métrica adotada como critério de otimização. Na literatura, as otimizações se dão diretamente pela análise do FOM das imagens, ou da máxima diminuição de ruído, ou seja, se preocupam apenas com a visibilidade do objeto de interesse. Já neste trabalho, foi realizada uma otimização para a estimativa de microcalcificações, 
considerando os mapas de FOM como uma das ferramenta de otimização e não o principal fator da escolha das energias. Este fato, em conjunto à utilização de diferentes detectores por cada autor, explica a diferença nas escolhas das combinações.

Em suma, se pode dizer que as condições otimizadas neste trabalho são muitos sensíveis às espessuras de mama, já que fica evidenciado, o deslocamento das escolhas ótimas das energias para a variação da espessura mamária. Isto pode servir de base para estudos mais complexos envolvendo a escolha de energias ótimas para a quantificação da espessura das calcificações e frações glandulares. 


\section{Capítulo 5}

\section{Conclusões e Perspectivas Futuras}

\subsection{Conclusões}

\subsubsection{Sobre a utilização do código PENELOPE adaptado e aquisição das imagens.}

O código PENELOPE foi validado através dos testes realizados. As diferenças entre os resultados obtidos e aqueles apresentados na literatura, para valores de SPR e DgN foram devidamente justificados, permitindo o uso deste código nas demais simulações.

A geração das imagens foi devidamente validada, já que os números de fótons que chegaram no detector, durante as aquisições, foram próximos aos previstos teoricamente.

O estudo das imagens geradas mostrou que a visualização das calcificações é prejudicada com o aumento da espessura da mama, e da energia do feixe utilizado, além de mostrar um limite de visualização para a espessura das microcalcificações. Este estudo também ressaltou a importância de se considerar a dose que a mama receberá em um teste, pois este parâmetro influência diretamente na redução de ruído das imagens, porém em grandes quantidades, pode gerar efeitos negativos na mama, como o surgimento de carcinomas [104]. A ponderação entre a visibilidade dos objetos e a dose absorvida na mama, realizada na etapa de otimização, foi de grande importância para a escolha das combinações ótimas. 


\subsubsection{Sobre a aplicação dos algoritmos de pré-processamento, combinação e pós-processamento}

O algoritmo de espalhamento implementado permitiu a redução média de 90\% dos fótons espalhados em cada imagem, estando de acordo com o esperado, validando desta forma, sua implementação e uso na imagem combinada.

A propagação do ruído também foi comprovada, mostrando-se necessária a aplicação do algoritmo de pós-processamento. Dos métodos estudos, o proposto por Kalender [79] (filtro KNR) teve um desempenho melhor, permitindo uma redução de cerca de $90 \%$ do ruído das imagens, além de realçar as calcificações.

\subsubsection{Sobre a otimização das imagens}

As combinações ótimas quantificam as espessuras reais das microcalcificações com alta precisão. A estimativa da fração glandular se mostrou eficiente, praticamente para qualquer escolha de energias combinadas (desde que a combinação não fosse realizada para energias muito próximas), tendo uma exatidão maior que $90 \%$ para as combinações ótimas.

As combinações escolhidas pareceram consistentes com as observadas na literatura, porém, divergências entre os resultados eram esperadas, já que este estudo otimizou a quantificação da fração glandular e da espessura das calcificações, enquanto a literatura geralmente se preocupou apenas em otimizar a visualização de calcificações.

\subsubsection{Sobre as limitações encontradas}

A maior limitação encontrada neste projeto, foi o tempo de simulação das imagens, algumas chegando a demorar semanas, dependendo da energia do feixe e da espessura da mama. O algoritmo de correção de espalhamento também consumiu muito tempo (cerca de uma hora por imagem).

\subsection{Perspectivas Futuras}

Apesar deste trabalho não poder ser aplicado diretamente em casos clínicos (devido à utilização de feixes monoenergéticos), ele serve de base para futuras 
simulações mais complexas. É proposto um estudo de otimização mais detalhado, onde será utilizado feixes polienergéticos nas simulações de imagens, levando em conta diversos tipos de detectores reais.

Para acelerar o tempo de otimização, é previsto um projeto para se paralelizar o código PENELOPE [31].

Após a execução destas etapas, seria interessante a aplicação clínica deste estudo, utilizando fantomas que se aproximem da mama real, de modo a se adquirir imagens reais que possam confirmar os resultados obtidos pelas simulações. 


\section{Referências Bibliográficas*}

[1] Instituto Nacional do Câncer. Instituto Nacional do Cancer - Estimativa 2016. Ministério Da Saúde, v. 1, n. 1, p. 51, 2016.

[2] Instituto Nacional do Câncer. Instituto Nacional do Cancer - Estimativa 2016. Ministério Da Saúde, Rio de Janeiro, v. 1, n. 1, p. 124, 2014.

[3] Instituto Nacional de Câncer. Controle do câncer de mama: documento de consenso. [S.1.], 2004. 37p. p.

[4] BAKER, R. et al. New relationships between breast microcalcifications and cancer. British Journal of Cancer, Nature Publishing Group, v. 103, n. 7, p. 1034-1039, 2010.

[5] WOLFE, J. N. Breast Patterns As Index of Breast. AJR Am J Roentgenol, v. 126, p. 1130-1139, 1976.

[6] HARVEY, J. A.; BOVBJERG, V. E. Quantitative assessment of mammographic breast density: relationship with breast cancer risk. Radiology, v. 230, n. 1, p. 29-41, 2004.

[7] KUCHIKI, M.; HOSOYA, T.; FUKAO, A. Assessment of Breast Cancer Risk Based on Mammary Gland Volume Measured with Ct. Breast Cancer: Basic and Clinical Research, n. 4, p. 57-64, 2010.

[8] KAPPADATH, S. C.; SHAW, C. C. Dual energy digital mammography for calcification imaging: theory and implementation. SPIE, v. 5368, n. 19, p. 751-760, 2004.

*De acordo com a Associação Brasileira de Normas Técnicas. NBR 6023. 
[9] WHEELER, F. W. et al. Micro-calcification detection in digital tomosynthesis mammography. Medical Imaging 2006: Image Processing, v. 6144, p. 614420+, 2006.

[10] DUCOTE, J. L.; MOLLOI, S. Quantification of breast density with dual energy mammography: an experimental feasibility study. Medical physics, v. 37, n. 2, p. 793-801, 2010.

[11] JOHNS, P. C. et al. Dual-energy mammography: initial experimental results. Medical physics, v. 12, n. 3, p. 297-304, 1985.

[12] SHAW, C. C.; GUR, D. Comparison of three different techniques for dual-energy subtraction imaging in digital radiography: A signal-to-noise analysis. Journal of Digital Imaging, v. 5, n. 4, p. 262-270, 1992.

[13] BRETTLE, D. S.; COWEN, A. R. Dual-energy digital mammography utilizing stimulated phosphor computed radiography. Phys. Med. Biol., v. 39, n. 11, p. 1989-2004, 1994.

[14] LEMACKS, M. et al. A dual-energy subtraction technique for microcalcification imaging in digital mammography: A signal-to-noise analysis. Medical Physics, v. 29, n. 8, p. 1739, 2002.

[15] BLIZNAKOVA, K.; KOLITSI, Z.; PALLIKARAKIS, N. Dual-energy mammography: simulation studies. Physics in Medicine and Biology, v. 51, n. 18, p. 4497-4515, 2006.

[16] GOMI, T. Dual-Energy Subtraction X-Ray Digital Tomosynthesis: Basic Physical Evaluation. Open Journal of Medical Imaging, v. 02, n. September, p. 111-117, 2012.

[17] JOHNS, P.; YAFFE, M. J. Theoretical optimization of dual-energy x-ray imaging with application to mammography. Medical physics, v. 12, n. 3, p. 289-296, 1985.

[18] ASAGA, T. et al. Dual-energy subtraction mammography. Journal of Digital Imaging, v. 8, n. 1 Supplement, p. 70-73, 1995. 
[19] LAIDEVANT, A. D. et al. Compositional breast imaging using a dual-energy mammography protocol. Medical physics, v. 37, n. 1, p. 164-74, 2010.

[20] LAM, A. R.; DING, H.; MOLLOI, S. Quantification of breast density using dual-energy mammography with liquid phantom calibration. Phys. Med. Biol., v. 59, n. 14, p. 3985-4000, 2014.

[21] SPYROUT, G. et al. Monte Carlo generated mammograms : development and validation. Phys. Med. Biol, v. 43, 1998.

[22] PEPLOW, D. E.; VERGHESE, K. Digital mammography image simulation using Monte Carlo. Medical physics, v. 27, n. 3, p. 568-579, 2000.

[23] BLIZNAKOVA, K. et al. A three-dimensional breast software phantom for mammography simulation. Physics in medicine and biology, v. 48, n. 22, p. 3699-3719, 2003.

[24] HUNT, R. A. et al. Calculation of the properties of digital mammograms using a computer simulation. Radiation Protection Dosimetry, v. 114, n. 1-3, p. 395-398, 2005.

[25] GONG, X. et al. A computer simulation study comparing lesion detection accuracy with digital mammography, breast tomosynthesis, and cone-beam CT breast imaging. Medical physics, v. 33, n. 4, p. 1041-1052, 2006.

[26] TOWBin, A. J.; PATERSON, B. E.; CHANG, P. J. Computer-based simulator for radiology: an educational tool. Radiographics : a review publication of the Radiological Society of North America, Inc, v. 28, n. 1, p. 309-316, 2008.

[27] KOUKOU, V. et al. Dual Energy Method for Breast Imaging : A Simulation Study. Computational and Mathematical Methods in Medicine, v. 2015, p. 8, 2015.

[28] DUCOTE, J. L.; MOLLOI, S. Quantification of breast density with dual energy mammography: A simulation study. Medical Physics, v. 35, n. 12, p. 5411-5418, 2008. 
[29] Del Lama, L.; GODELI, J.; POLETTI, M. Monte Carlo simulation studies for the determination of microcalcification thickness and glandular ratio through dual-energy mammography. Radiation Physics and Chemistry, Elsevier, p. 1-6, 2016.

[30] CERN. GENT4. 2016. Disponível em: <https://geant4.web.cern.ch/geant4/>.

[31] SALVAT, F.; FERNÁNDEZ-VAREA, J. M.; SEMPAU, J. P ENELOPE-2008 : A Code System for Monte Carlo Simulation of Electron and Photon Transport A Code System for Monte Carlo. Paris, France, 2008.

[32] KHAN, F. M. The Physics of Radiation Therapy. 4. ed. [S.l.]: Lippincot Williams \& Wilkin, 2003.

[33] BOONE, J. M.; YU, T.; SEIBERT, A. Mammography spectrum measurement using an x-ray diffraction device. Physics in medicine and biology, v. 43, n. 9, p. 2569-82, 1998.

[34] SIEMENS. Simulation of X-ray Spectra. 2016. Disponível em: $<$ http://www.oem-products.siemens.com/x-ray-spectra-simulation>.

[35] ATTIX, F. H. Introduction to radiological physics and radiation dosimetry. 1. ed. [S.l.]: WILEY-VCH Verlag GmbH \& Co, 2004.

[36] HIGGINS, P. D. et al. Mass energy-transfer and mass energy-absorption coefficients, including in-flight positron annihilation for photon energies $1 \mathrm{keV}$ to $100 \mathrm{MeV}$. [S.l.], 1992. $4812 \mathrm{p}$.

[37] JOHnS, H. E.; CUnNInghAM, J. R. The Physics of Radiology. 4. ed. Springfield, Illinois. E.U.A.: Charles C. Thomas, 1983.

[38] HUBBEL, J. H. et al. Atomic Form Factors, Incoherent Scattering Functions, and Photon Scattering Cross Sections. The Journal of Physical Chemistry A, v. 4, n. 3, p. 472-538, 1975.

[39] HOSSAIN, I. Compton scattering of $662 \mathrm{keV}$ gamma rays proposed by klein-nishina formula. Scientific Research and Essays, v. 6, n. 30, p. 6312-6316, 2011. 
[40] BERGER, M. J.; HUBBELL, J. H. XCOM: Photon Cross Sections on a Personal Computer. [S.1.], 1987. 87-3597 p.

[41] JACKSON, D. F.; HAWKES, D. J. X-ray attenuation coefficients of elements and mixtures. Physics Reports, v. 70, n. 3, p. 169-233, 1981.

[42] SPRAWLS, P. Physical Principles of Medical Imaging. 2. ed. Madison, Wisconsin. E.U.A.: Medical Physics Publishing, 1995.

[43] BARNES, G. T. Contrast and scatter in x-ray imaging. Radiographics, v. 11, n. 6, p. 307-323, 1991.

[44] CARLSSON, G. A. et al. Generalised use of contrast degradation and contrast improvement factors in diagnostic radiology. Application to vanishing contrast. Physics in Medicine ES Biology, v. 31, n. 7, p. 737-749, 1986.

[45] MOTZ, J. W.; DANOS, M. Image information content and patient exposure. Medical Physics, v. 12, n. 1, p. 5-12, 1978.

[46] WAGNER, A. J. Contrast and grid performance in mammography. In screen film mammography: Imaging Considerations and Medical Physics Responsabilities, eds. G.T. Barnes and G.D. Frey. Medical Physics, p. 115-134, 1991.

[47] FAHRIG, R.; YAFFE, M. A model for optimization of spectral shape in digital mammography. Medical Physics, v. 21, n. 9, p. 1463-1471, 1994.

[48] BARNES, G. T.; BREZOVICH, I. A. The intensity of scattered radiation in mammography. Radiology, v. 126, n. 1, p. 243-247, 1978. ISSN 0033-8419.

[49] BUSHBERG, J. T. et al. The Essential Physics of Medical Imaging. 2. ed. Philadelphia, PA. E.U.A.: Lippincott Williams \& Wilkins, 2002.

[50] FAHRIG, R.; YAFFE, M. Optimization of spectral shape in digital mammography: dependence on anode material, breast thickness, and lesion type. Medical Physics, v. 21, n. 9, p. 1473-1481, 1994. 
[51] HAMMERSTEIN, R. G. et al. Absorbed Radiation Dose in Mammography. Radiation Physics, v. 130, p. 485-491, 1979.

[52] STANTON, L. et al. Dosage Evaluation In Mammography. Radiology, v. 150, p. $577-584,1984$.

[53] DANCE, D. R.; YOUNG, K. C.; ENGEN, R. E. van. Estimation of mean glandular dose for breast tomosynthesis: factors for use with the UK, European and IAEA breast dosimetry protocols. Physics in medicine and biology, v. 56, n. 2, p. 453-471, 2009.

[54] DANCE, D. R. Monte Carlo calculation of conversion factors for the estimation of mean glandular breast dose. Physics in medicine and biology, v. 35, n. 9, p. 1211-1219, 1990 .

[55] WU, X.; BARNES, T.; TUCKER, M. Spectral dependence of glandular tissue dose in screen-film mammography. Radiology, v. 179, n. 1, p. 143-148, 1991.

[56] BOONE, J. Glandular breast dose for monoenergetic and high-energy x-ray beams: Monte Carlo assessment. Radiology, v. 203, p. 23-37, 1999.

[57] CUNHA, D. M.; TOMAL, A.; POLETTI, M. E. Evaluation of scatter-to-primary ratio, grid performance and normalized average glandular dose in mammography by Monte Carlo simulation including interference and energy broadening effects. Physics in Medicine \& Biology, v. 55, n. 15, p. 4335-4359, 2010.

[58] WU, X. et al. Normalized average glandular dose in molybdenum target-rhodium filter and rhodium target-rhodium filter mammography. Radiology, v. 193, p. 83-89, 1994.

[59] ACR. Mammography quality control manual, Medical physicist's section, Technical Report. [S.1.], 1999.

[60] DANCE, D. R. et al. Additional factors for the estimation of mean glandular breast dose using the UK mammography dosimetry protocol. Physics in medicine and biology, v. 45, n. 11, p. 3225-3240, 2000. 
[61] ZOETELIEF, J.; JANSEN, J. Calculation of air kerma to average glandular tissue dose conversion factors for mammography. Radiat Prot. Dosim., v. 57, n. 1-4, p. 397-400, 1995.

[62] OBENAUER, S.; HERMANN, K.; GRABBLE, E. Dose reduction in full-field digital mammography: an anthropomorphic breast phantom study. British Journal of Radiology, v. 76, n. 2, p. 291-303, 2003.

[63] AYMAN, A. E. Calibration of Working Standard Ionization Chambers and Dose Standardization. 76 p. Tese (Dissertação de mestrado) - University of Khartoum, 2011.

[64] BOONE, J. M. Normalized glandular dose (DgN) coefficients for arbitrary X-ray spectra in mammography: computer-fit values of Monte Carlo derived data. Medical physics, v. 29, n. April, p. 869-875, 2002.

[65] BARRA, F.; BARRA, R.; SOBRINHO, A. B. Novel functional methods in the evaluation of breast lesions. Radiol. Bras., v. 45, n. 6, p. 340-344, 2012.

[66] ALVAREZ, R. E.; MACOVSKI, A. Energy-selective reconstructions in X-ray computerized tomography. Physics in medicine and biology, v. 21, n. 5, p. 733-744, 1976.

[67] LEHMANN, L. A. et al. Generalized image combinations in dual KVP digital radiography. Medical Physics, v. 8, n. 5, p. 659-667, 1981.

[68] ASAGA, T. et al. Breast Imaging: Dual-Energu Projection Radiography with Digital Radiography. Radiology, v. 164, n. 3, p. 869-870, 1987.

[69] BOONE, J. M.; SHABER, G. S.; TECOTZKY, M. Dual-energy mammography: a detector analysis. Medical physics, v. 17, n. 4, p. 665-675, 1990. ISSN 00942405.

[70] ERGUN, L. et al. Single-exposure dual-energy computed radiography: improved detection and processing. Radiology, v. 1, n. 174, p. 243-249, 1990.

[71] CHAN, H. P.; DOI, K. Radiation dose in diagnostic radiology: Monte Carlo simulation studies. Medical physics, v. 11, n. 4, p. 480-90, 1984. 
[72] BOONE, J. M.; COOPER, V. N. Scatter/primary in mammography: Monte Carlo validation. Medical Physics, v. 27, n. 8, p. 1818-31, 2000.

[73] HUBBELl, J. H.; SELTZER, S. M. Tables of X-Ray Mass Attenuation Coefficients and Mass Energy-Absorption Coefficients from $1 \mathrm{keV}$ to $20 \mathrm{MeV}$ for Elements $Z=1$ to 92 and 48 Additional Substances of Dosimetric Interest. [S.1.], 1996.

[74] DUCOTE, J. L.; MOLLOI, S. Scatter correction in digital mammography based on image deconvolution. Physics in medicine and biology, v. 55, p. 1295-1309, 2010 .

[75] BOONE, J. M.; SEIBERT, J. a. An analytical model of the scattered radiation distribution in diagnostic radiology. Medical physics, v. 15, n. 5, p. 721-725, 1988.

[76] KAPPADATH, S.; SHAW, C. C. Dual energy digital mammography for calcification imaging: Scatter and nonuniformity corrections. Medical Physics, v. 32, n. 11, p. 3395-3408, 2005.

[77] SAliVAHANAN, S.; VALlAVARAJ, A.; GNANAPRIYA, C. Digital Signal Processing. 21. ed. New Delhi, India.: Tata McGraw-Hill, 2007.

[78] KAPPADATH, S. C.; SHAW, C. C. Dual energy digital mammography for calcification imaging: noise reduction techniques. Physics in medicine and biology, v. 53, n. 19, p. 5421-43, 2008.

[79] KALENDER, W. A.; KLOTZ, E.; KOSTARIDOU, L. Algorithm for noise suppression in dual energy ct material density images. IEEE Transactions on Medical Imaging, v. 7, n. 3, p. 218-224, 1988.

[80] SAMEI, E. et al. A framework for optimising the radiographic technique in digital X-ray imaging. Radiation Protection Dosimetry, v. 114, n. 1-3, p. 220-229, 2005.

[81] KLAUSZ, R.; SHRAMCHENKO, N. Dose to population as a metric in the design of optimised exposure control in digital mammography. Radiation Protection Dosimetry, v. 114, n. 1-3, p. 369-374, 2005. 
[82] BALDELLI, P.; PHELAN, N.; EGAN, G. Investigation of the effect of anode/filter materials on the dose and image quality of a digital mammography system based on an amorphous selenium flat panel detector. British Journal of Radiology, v. 83, n. 988, p. 290-295, 2010.

[83] BORG, M.; BADR, I.; ROYLE, G. The use of a figure-of-merit (FOM) in digital mammography. Radiation Protection Dosimetry, v. 151, n. 1, p. 81-88, 2012.

[84] MCMASTER, W. H. et al. Compilation of X-ray Cross Sections. [S.l.], 1969.

[85] STORM, E.; ISRAEL, H. I. Photon Cross Sections from 1 keV to $100 \mathrm{MeV}$ for Elements $Z=1$ to $Z=100$. [S.l.], 1970 .

[86] CUllen, D. E; HUBBelL, J. H.; KISSEL, L. The Evaluated Photon Data Library. [S.1.], 1997.

[87] SPELLER, R. Tissue analysis using x-ray scattering. X-Ray Spectrometry, v. 28, n. February, p. 224-250, 1999.

[88] PERSLIDEN, J.; CARLSSON, G. A. Scatter rejection by air gaps in diagnostic radiology. Calculations using a Monte Carlo collision density method and consideration of molecular interference in coherent scattering. Physics in medicine and biology, v. 42, n. 1, p. 155-175, 1997.

[89] MORIN, L. R. M. Molecular Form Factors and Photon Coherent Scattering Cross Sections of Water. Journal of Physical and Chemical Reference Data, v. 11, n. 4, p. 1091-1098, 1982.

[90] HUBBELL, J. H.; OVERBO, I. Relativistic atomic form factors and photon coherent scattering cross sections. 1979. 69-106 p.

[91] BOONE, J. M.; FEWELL, T. R.; JENNINGS, R. J. Molybdenum, rhodium, and tungsten anode spectral models using interpolating polynomials with application to mammography. Medical physics, v. 24, n. 12, p. 1863-1874, 1997.

[92] POON, E.; VERHAEGEN, F. Accuracy of the photon and electron physics in GEANT4 for radiotherapy applications. Medical Physics, v. 32, n. 6, p. 1696, 2005. 
[93] DANCE, D. R.; DAY, G. J. The computation of scatter in mammography by Monte Carlo methods. Physics in Medicine and Biology, v. 29, n. 3, p. 237-247, 1984.

[94] HELVIE, M. A. et al. Breast Tickness in Routine Mammograms: Effect on Image Quality and Radiation Dose. AJR Am J Roentgenol, v. 163, n. 6, p. 1371-1374, 1994.

[95] LANCONELLI, N. et al. Optimization of the acquisition parameters for a SPET system dedicated to breast imaging. IEEE Nuclear Science Symposium Conference Record, v. 5, n. December, p. 2959-2962, 2007.

[96] TAVAKOLI, M. B. et al. Evaluation of the relation between breast glandular absorbed dose and radiographic quality in mammography. Iranian Journal of Radiation Research, v. 6, n. 2, p. 79-84, 2008.

[97] CARLSSON, C. A.; CARLSSON, G. A. Basic physics of X-ray imaging. Linkoping, Suécia., 1996. 3-29 p.

[98] ROSE, A. The sensitivity performance of the human eye on absolute scale. Journal of the Optical Society of America A, v. 38, p. 196-208, 1948.

[99] DICKERSCHEID, D. et al. Contrast-noise-ratio (CNR) analysis and optimisation of breast-specific gamma imaging (BSGI) acquisition protocols. EJNMMI research, v. 3, n. 21, 2013.

[100] BURGESS, A. E. The Rose model, revisited. Journal of the Optical Society of America A, v. 16, n. 3, p. 633, 1999.

[101] United States Nuclear Regulatory Commission. ALARA. 2016. Disponível em: <http://www.nrc.gov/reading-rm/basic-ref/glossary/alara.html>.

[102] AMINAH, M. et al. Optimal beam quality selection based on contrast-to-noise ratio and mean glandular dose in digital mammography. Australasian Physical and Engineering Sciences in Medicine, v. 33, n. 4, p. 329-334, 2010.

[103] BOONE, J. M. Color mammography. Image generation and receiver operating characteristic evaluation. Invest. Radiol., v. 26, n. 6, p. 521-7, 1991. 
[104] HENDRICK, R. E. Radiation doses and cancer risks from breast imaging studies. Radiology, v. 257, n. 1, p. 246-53, 2010. 